\title{
WestVirginiaUniversity
}

THE RESEARCH REPOSITORY @ WVU

Graduate Theses, Dissertations, and Problem Reports

2008

\section{Feeding behaviors and performance measurements in bucks, rams, and bulls}

Stephen John Chavez

West Virginia University

Follow this and additional works at: https://researchrepository.wvu.edu/etd

\section{Recommended Citation}

Chavez, Stephen John, "Feeding behaviors and performance measurements in bucks, rams, and bulls" (2008). Graduate Theses, Dissertations, and Problem Reports. 2627.

https://researchrepository.wvu.edu/etd/2627

This Thesis is protected by copyright and/or related rights. It has been brought to you by the The Research Repository @ WVU with permission from the rights-holder(s). You are free to use this Thesis in any way that is permitted by the copyright and related rights legislation that applies to your use. For other uses you must obtain permission from the rights-holder(s) directly, unless additional rights are indicated by a Creative Commons license in the record and/ or on the work itself. This Thesis has been accepted for inclusion in WVU Graduate Theses, Dissertations, and Problem Reports collection by an authorized administrator of The Research Repository @ WVU. For more information, please contact researchrepository@mail.wvu.edu. 


\title{
Feeding Behaviors and Performance Measurements in Bucks, Rams, and Bulls
}

\author{
Stephen John Chavez
}

Thesis submitted to the Davis College of Agriculture, Forestry, and Consumer Sciences at West Virginia University in partial fulfillment of the requirements

for the degree of

\author{
Master of Science \\ in \\ Animal and Nutritional Sciences
}
Eugene E. D. Felton, Ph.D., chair John Warren, Ph.D. Hillar Klandorf, Ph.D.

Division of Animal and Nutritional Sciences

\author{
Morgantown, West Virginia \\ 2008
}

Keywords: residual feed intake, behavior, ram, goat, bull, intake, performance, feed intake 


\author{
ABSTRACT \\ Feeding Behaviors and Performance Measurements \\ in Bucks, Rams, and Bulls
}

\title{
Stephen John Chavez
}

The objective of the study was to determine if relationships exist with feeding behaviors of bucks, rams, and bulls and efficiency or residual feed intake (RFI). Animals utilized in this investigation were either producer consigned by species or West Virginia University animals. All animals were group-housed in pens (14.6 m x $51.2 \mathrm{~m})$ with 156.2 $\mathrm{m}^{2}$ under roof at the Reymann Memorial Farm in Wardensville, WV over two years. Animals were fed complete nutritionally adequate rations ad libitum to meet daily growth requirements for each species. GrowSafe radio frequency technology (GrowSafe Systems Ltd.) was used to monitor animal identification, visit time and location, duration, and feed displacement. Allflex ${ }^{\circledR}$ transponders were placed in each animal's left ear. Eight pens had three feed nodes, while two pens had four. Rams and bucks were housed in the pens with four feed nodes. Modifications were made to the feed nodes for the ram and buck research to prevent more than one animal from feeding at one time. Statistical analyses were completed using Proc FREQ, TTEST, and GLM of SAS. More efficient animals consumed less feed $(P<0.01)$ and visited the feed nodes less frequently $(P<$ $0.01)$. Negative RFI goats and the rams in the first year had fewer feeding and nonfeeding bouts $(P<0.05)$. Most visits occurred during the day $(P<0.01)$ for all species. Daily feed intake varied in all species $(P<0.01)$. Individual differences were seen in each species with other behaviors and performance measurements. Although behavioral differences were seen with RFI in all species, a more complete behavioral analysis is required to understand how dominance behavior and behavior allocation affect energy expenditure and intake. 


\section{ACKNOWLEDGEMENTS}

I begin by thanking Dr. Eugene Felton for giving me the opportunity to work as one of his graduate students and expanding my horizon in animal science. Previously having minimal experience with beef cattle, my experience at West Virginia University has opened a new window of opportunities. Also, I thank Dr. Janet Tou for her guidance and leadership while preparing to further my education after my studies at West Virginia University along with the many faculty members that have provided constructive criticism to help shape my way of thinking and develop ideas pertinent to a career in animal science.

The graduate students in the department of animal and nutritional sciences are greatly appreciated for all their guidance and assistance over the past two years. Finally, I thank my family and friends for their support. 


\section{TABLE OF CONTENTS}

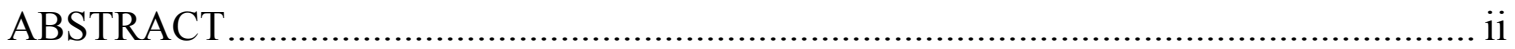

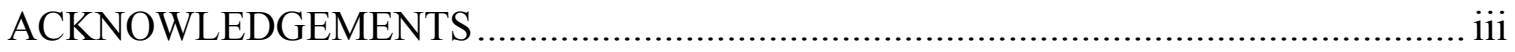

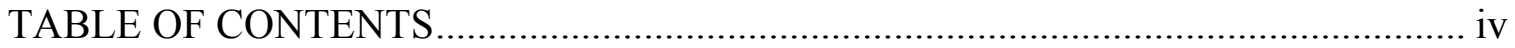

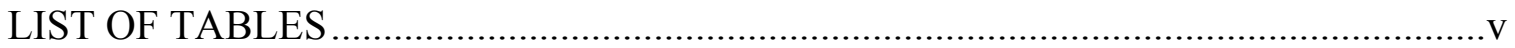

LIST OF FIGURES ..................................................................................... vi

LIST OF ABBREVIATIONS USED ….............................................................. vii

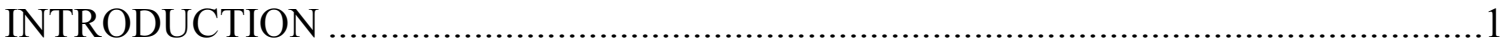

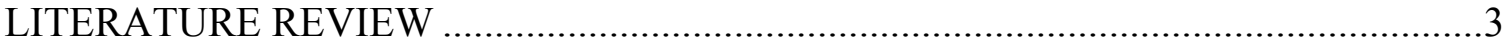

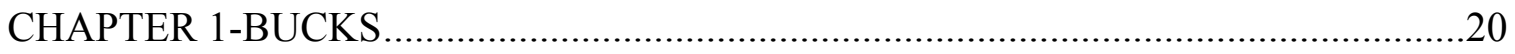

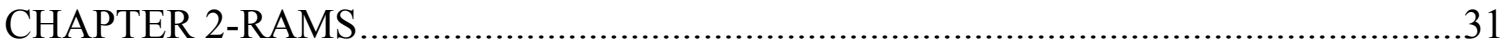

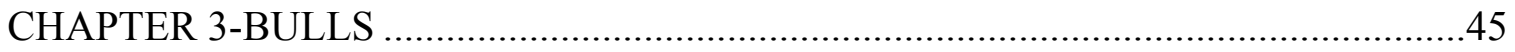

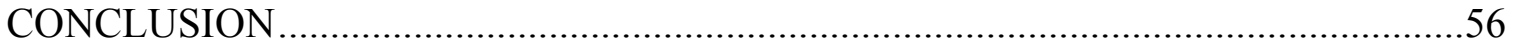

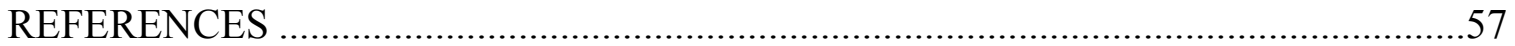




\section{LIST OF TABLES}

Bucks

Table 1. Descriptive statistics for positive and negative RFI bucks .....................64

Table 2. Production measurements between negative and positive RFI ..............65

Table 3. Production measurements as affected by birth number .........................66

Table 4. Percentage of meals during each time period ....................................67

Table 5. Descriptive statistics for goat means per visit ....................................68

Table 6. Feeding behavior means per time period .............................................69

Table 7. Percentage of observations at each scale for each time period................70

Rams

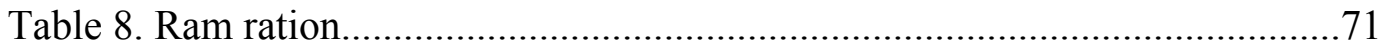

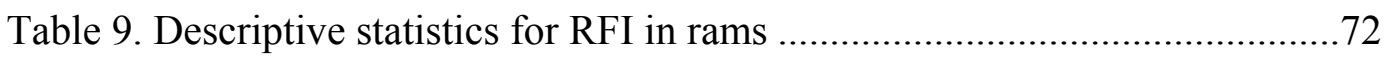

Table 10. Descriptive statistics for birth number in rams ..................................73

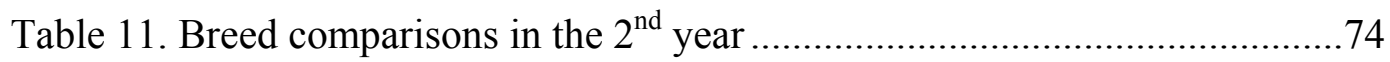

Table 12. Descriptive statistics for ram means per visit ..................................75

Table 13. Feeding behavior means per time period in year 1 rams ......................76

Table 14. Feeding behavior means per time period in year 2 rams .....................77

Bulls

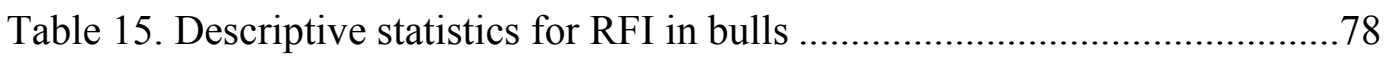

Table 16. Descriptive statistics for bull means per visit ................................79

Table 17. Feeding behavior means per time period in bulls .............................80

Table 18. Mean values for bulls during first and last 50 days of study ................81

Table 19. Mean differences by pen for bulls ....................................................82 


\section{LIST OF FIGURES}

Figure 1. Modifications to prevent multiple goats from eating at once...........................83

Figure 2. Modifications to GrowSafe ${ }^{\circledR}$ feed node with Kane ${ }^{\circledR}$ nursery feeder ................84

Figure 3. Mean daily intake for positive and negative RFI bucks................................85

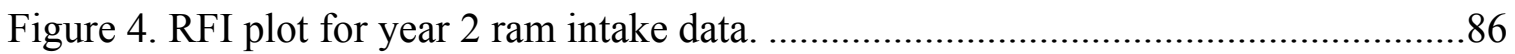

Figure 5. Mean daily intake for Year 1 positive and negative RFI rams........................87

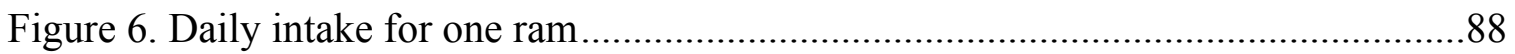

Figure 7. Mean daily intake for Year 2 positive and negative RFI rams........................89

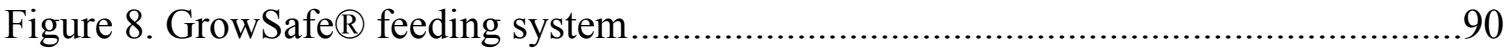

Figure 9. Mean daily intake for positive and negative RFI bulls.................................91 


\section{LIST OF ABBREVIATIONS}

ADG- average daily gain

RFI- residual feed intake

SC- scrotal circumference

REA- ribeye area

LEA- loineye area

BF- backfat

IMF- intramuscular fat

FI- feed intake

FCR- feed conversion ratio

F:G- feed:gain

HH- hip height 


\section{INTRODUCTION}

In any livestock production system, one of the largest costs associated with production are the costs of feeding the animals. In genetic selection of production animals, the producer's goal is to find the best animals that will produce the most on the least amount of feed. Using a high quality feedstuff is a fast, but expensive way to increase the desired yield of end product. Most production industries utilize several measurements to evaluate animals for efficiency so that the gains exceed the costs. Common measures of efficiency include gain:feed ratio, feed:gain ratio and residual feed intake (RFI).

RFI is rapidly becoming the common method of evaluating efficiency in animals. RFI is calculated using regression analysis of the actual amount of feed consumed against the predicted amount of feed (Arthur, 1996). RFI has been shown to be heritable in both sheep and cattle (Snowder \& Van Vleck, 2003; Archer et al., 1997). Thus, selection for superior efficiency is possible.

Feeding behaviors can also affect the efficiency and cost of a growing animal. Feeding rate, duration of feeding and feed intake affect RFI (Rauw et al., 2006a; Rauw et al., 2006b). Feeding frequency, feed intake and activity level are different between each animal. Social interactions among animals will also affect when and how often an animal will eat. When given multiple locations for food, animals may select to eat from a

preferred location (Brouns, 1994). Although behavior is an important factor in efficiency, the producer's main objective is looking at animal performance. 
Animals are evaluated using common production measurements, such as average daily gain (ADG), scrotal circumference (SC), backfat thickness, and ribeye area (REA), to determine if an animal should be kept for breeding. Larger scrotal circumference is often a desired characteristic in male animals for higher semen quality and increased sperm production (Kriese et al., 1991). Ultrasound measurements are used to determine fat thickness and ribeye area in cattle for carcass quality. While performance measurements and feeding behavior are important to producers, each species may have variation in what factors are affected by efficiency.

Individual feeding behavior, intake, and performance measurements were collected from three species in young sire evaluation programs. Three similar data analyses were conducted for young bucks, rams and bulls. The objectives of the analysis are: 1) to determine relationships between feeding behaviors and RFI, 2) to compare feeding behaviors among bucks, bulls and rams and 3) to determine if feeding behaviors are predictors of common production measurements used for industry. 


\section{REVIEW OF LITERATURE}

\section{Efficiency and performance measurements}

Over time, more methods of measuring efficiency have evolved. Average daily gain (ADG) was a desirable production trait with which animals reached desirable slaughter weight; however, with increasing costs for feed, animals that gain more and eat less are favored. Feed conversion ratios are calculated by measuring the amount of feed consumed and dividing by weight gained (Arthur et al., 1996). Feed conversion ratios are not the most accurate method for measuring efficiency because the conversion does not incorporate maintenance requirements. Feed conversion ratios do not accurately predict for genetic merit since the feed conversion ratio does not reflect change in component traits (Arthur et al., 2001). RFI is based on a linear index where the genetic change is predictable.

Residual feed intake (RFI) has become the preferred method of measuring efficiency. Arthur et al. (1996) defined residual or net feed intake as "the difference between actual feed intake and the expected feed requirements for maintenance of body weight and some measure of production." Throughout several years of research, RFI has been shown to be a heritable trait that could help breeding programs. Snowder and Vleck (2003) report a heritability estimate of 0.26 in sheep. Archer et al. (1997) reported a heritability estimate of 0.62 in beef cattle and found heritability estimates for feed conversion and ADG to be 0.42 and 0.35 , respectively. Nguyen et al. (2005) found heritability estimates around 0.23 in swine using three different models for RFI. Variation in feed digestibility, physical activity, thermo-regulation, basal metabolism, production requirements, and energy partitioning all affect individual animal efficiency. 
Arthur et al. (1996; 2001) found a correlation between RFI and feed intake, feed conversion (FCR), and fat depth in cattle. No relationship was seen with efficiency and loin eye muscle area, scrotal circumference (SC), ADG, and weight. Baker et al. (2006) found similar results with high or positive RFI steers having a higher intake and feed conversion ratio. They found no relation between RFI and the following performance measurements: quality and yield grades, marbling score, fat thickness, longissimus muscle area, and hot carcass weight. No relationship was found with quality attributes, including taste of product and RFI; therefore, producers and consumers will see no negative effects if cattle are bred for efficiency based upon RFI.

Schenkel et al. (2004) reported that heritability coefficients for BF, longissimus muscle area, intramuscular fat (IMF), feed intake (FI), FCR, RFI, ADG, metabolic midweight, hip height $(\mathrm{HH})$, and $\mathrm{SC}$ in young beef bulls. SC has no relationship to RFI; however, a genetic correlation exists with $\mathrm{SC}$ and $\mathrm{FI}, \mathrm{BF}, \mathrm{HH}$, and metabolic midweight. This relationship is probably due to the larger body size in bulls that have larger SC. No relationship was found with RFI and ADG, metabolic midweight, or HH. A weak relationship was found with BF. If animals are more efficient at utilizing energy intake, less energy will be allocated for storage as fat.

Schenkel et al. (2004) hypothesized that more efficient animals are leaner because lean muscle requires less energy to deposit than fat, which is more energy expensive; however, fat is easier to maintain unlike the high turnover rate of protein in muscle. Castro Bulle et al. (2007) found that high growth steers had higher protein accretion. The rationale was that protein degradation decreased and/or protein synthesis increased. No differences were seen between groups with fractional synthesis rate or fractional 
degradation rate of myofibrillar protein. Basarab et al. (2003) found liver, stomach, and intestinal weights were lower in negative RFI steers. They reported that more efficient steer retained less energy stores and produced less heat.

Heat loss may be a factor in efficiency. If animals are past their critical temperature range they require increased heat production or expenditure. Nielson et al. (1997) found that heat expenditure is heritable in mice and that several factors account for the variability in heat loss other than heat loss from the utilization of energy. High and low heat expending mice had similar body weights; however, after the fourteenth generation, high expending heat mice had lower body fat. When comparing heat loss and efficiency, stage of production is very important. Mousel et al. (2001) found a difference between high and low growth lines of adult, non-lactating mice. Physical activity accounted for $36 \%$ of the feed intake and $11.5 \%$ of the heat loss differences. Luiting et al. (1991) claimed that RFI was influenced by physical activity; however, heat production should be included in efficiency models as well. Nkrumah et al. (2006) found that positive RFI cattle produced more methane gas and lost more energy in the form of methane. Low RFI cattle produced less heat and had higher energy retention.

Richardson et al. (2001) determined that less than five percent of variation in animal body composition results from genetic variation and that more efficient steers gained more protein while consuming less feed. Steer offspring of more efficient cattle had less rib fat and rump fat. Low RFI steers produced less residual heat per $\mathrm{kg}$ of protein gained. Carcass characteristics were similar at slaughter between low and high efficiency animals (McDonagh et al., 2001). No differences were seen in steer loin eye-muscle area, dressing percentage, or carcass weights. They found that more efficient steers had less 
subcutaneous fat over their rump and ribs. The difference in subcutaneous fat did not affect IMF, fat color, meat color, or marbling scores. Meat characteristics were not affected by RFI status; however, positive RFI steers had higher levels of calpastatin in the longissimus dorsi muscle. After several generations of selection for RFI, Richardson et al. (2001) suggested that the value of carcasses may be affected.

When measuring efficiency, the length of test required varies depending on several factors. Wang et al. (2006) determined the shortest test length to accurately reflect efficiency measurements. For cattle, a minimum of 63 days of feed intake data should be collected when calculating RFI and 42 days when calculating feed conversion. Body weight should be recorded weekly for the animals. Keeping animals past these lengths would not be cost effective if trying to increase accuracy. When missing observations, accurate measurements can be made for efficiency if all intake data is known for the first 35 days. These test durations are shorter than what Archer et al. (1997) had reported. Archer et al. determined accurate test lengths of 35 days for feed intake, and 70 days for RFI, feed conversion, and growth rate. Archer et al. determined weights could be collected every other week for accurate calculations.

At birthing, differences may appear between single and multiple birth offspring. After one year, no difference was seen in body weight between lambs from single or multiple births (Mandal et al., 2003). Single born lambs gained weight faster than multiple birth lambs until weaning; however, no difference was seen at one year. Lambs from multiple births had higher growth efficiency until three months of age. 


\section{Feeding behaviors}

During each day, animals will eat when they are hungry. Unlike humans, bulls, rams, and bucks do not consume a meal at once, but will consume a meal with small breaks in between. These smaller meals or visits to the feeder can be clustered together and considered feeding bouts. Feeding bouts are determined by criterion to differentiate one meal from the next. Several models have been established based on the motivation to eat by an animal (Tolkamp et al., 1998). Some research has shown that inter-meal and intra-meal intervals of six minutes should be the amount of time required to separate meals (Orr et al., 2001). In 2004, Allcroft et al. analyzed several models for feeding behavior. They concluded that a semi-Markov model would be the most applicable to differentiate between meals because it incorporates a long-term memory factor with satiety. Tolkamp et al. (2000) believe the best method for evaluating short-term feeding behavior is a meal and not individual feeding events.

Tolkamp et al. (2000) reports observations of dominant cows forcing submissive cattle from the feeder shortening the duration of visits. This variation in displacements from the feeder could increase the number of visits per cow. Dominance hierarchies would be a factor in feeding behaviors since not all meals end voluntarily. Number of feeding locations per cow also affects feeding duration and intake. Several factors should be considered when evaluating visits: place in social hierarchy, stocking density, and aggressiveness of other animals.

Olofsson (1999) compared two treatments of cows with milk production and pressure per feeder. The only correlation found was an increase in energy-corrected milk with an increased duration of eating. He found no relationship with number of visits per 
meals per day, eating rate, or daily intake. With an increased pressure for feed troughs, cows had shorter eating durations, faster eating rates, and consumed more feed. With increased competition and pressure per feeder, dominant cows were not affected with the amount of time spent eating. With time allocation and pressure for feeders, higher pressure for feeder resulted in a decreased time eating and increased time standing. No change occurred with lying, milking, or drinking times. Olofsson found that when the competition per feed trough was higher, cows spent more time feeding at night and subordinate cows were more likely to be adjusting daily behaviors.

Georgsson and Svendson (2002) reported similar findings for competitive environments in swine. They looked at one or two feed troughs per group of pigs and found that smaller pigs were prohibited from eating by the larger pigs. Small pigs had lower ADG and daily feed intake when access was to only one feed trough; however, the small pigs had a better G:F ratio. As a measure of efficiency, small pigs were better at converting energy to body weight. The small pigs given access to only one feed trough had a higher lean meat percentage than when given access to two.

Feeding behaviors in the swine varied when provided feed ad libitum or restricted and according to size (Georgsson and Svendson, 2002). When fed ad libitum, pigs had more feeding bouts if allowed access to two feed troughs per pen. Small and medium size pigs spent more time eating when given access to two feed troughs. If competition is increased, all pigs increased feeding bouts during the night and the increase was greatest for small pigs; however, eating rate did not increase. No difference was seen with nonfeeding bouts among pigs. Approximately one-third of feed was consumed at night for 
group-housed pigs. Allcroft et al. (2004) reported a similar meal pattern in cattle with one-third of feed consumption occurring at night.

Another management practice other than ad libitum and restricted feeding would be feeding every few days. Manninen et al. (2006) fed cattle daily or every three days. They found no difference with feeding frequency and milk production in either treatment. Cows fed daily spent more time outside and cows fed every three days spent more time lying; therefore, management practices will affect feeding behavior. No difference was seen in weight gain or body condition score.

Abijaoudé et al. (2000) found that goats have two large meals and several secondary meals throughout the day. The major difference between individual animals that may relate to efficiency and productivity is the number of secondary meals. Langhans et al. (1988) found pygmy goats ate about 12 meals per day. Eight meals were during daylight, which accounted for $63 \%$ of feed intake. The meals during daylight were smaller and had shorter intervals before completion of the meal, while fewer meals occurred at night. They found very few meals less than $50 \mathrm{~g}$ during the dark compared to the light phase. Ramli et al. (2005) determined that between $70-80 \%$ of the eating behavior was seen during the day (0600-1800). Feeding time was variable for each goat; however, goats ate 5-6 hours per day in the study.

Orr et al. (2001) found that the main meal in sheep grazing grass and clover occurred around 1800 . They also found that sheep decrease their eating rate towards the end of the meal. Tolkamp et al. (2000) reported that most meals start during the 0900 and 1700 hours for dairy cows. Most meals consumed were around 1000 and between 1600 
and 2000. Shabi et al. (2005) found lactating dairy cows have two main meals that peak around dusk and dawn demonstrating diurnal eating patterns.

Goats consume more meals per day than sheep (Morand-Fehr et al., 1991). Van et al. (2002) found that goats consume more meals than sheep both during the day and at night. Goats spend more total time eating and eat longer during the day than sheep. Goats and sheep spend the same amount of time eating during the night. Morand-Fehr et al. (1991) concluded that goats often eat slower than sheep because of selective grazing behaviors. Solanki (1994) found that goats selectively graze in a diurnal pattern with two main peaks. Solanki reported that goats consumed more grasses before noon and more shrubs and bushes in the evening. Although no difference was seen in eating rate, a difference was seen with bite size. Bite size was larger when consuming thorny bushes compared to grasses.

Throughout the grazing season, animals will vary the time spent eating. Each animal will eat until moving to a new location that is more favorable for optimal foraging. Pfister et al. (1988) found that total available forage is highly correlated with the amount of time a goat will spend eating at one location; however, they did not see the same result for sheep. During the dry season, sheep and goats consumed similar plant species and had similar feeding times. Goats increased feeding times per area during the wet season. During the early wet season, sheep ate while moving.

In each species, the animal has to decide how to allocate their time. In Mountain goats, Hamel and Côté (2008) found that goats will decrease lying time and increase foraging to meet energy demands. Lactating females will decrease lying time and increase time ruminating. On hot days mountain goats shifted time of feeding to dusk and 
dawn. Goats nursing males would forage longer than those nursing females. The researchers also concluded that dominant goats spent less time foraging and may be better adapted to finding food than subordinates or are capable of defending their resources.

\section{Efficiency and behavior}

Feeding behaviors appear to have a relationship with efficiency and performance measurements in animals. Common measurements include eating rate, frequency, and duration. Schwartzkopf-Genswein et al. (1999) found that as duration of feeding increased for cattle, so did the total daily intake. Conflicts among studies with these results may be due to eating rate. No relationship was found with frequency of visits and feed intake (Schwartzkopf-Genswein et al., 2002). In this study, cattle visited the feeder more often when fed ad libitum compared to restricted feeding regimes and a negative correlation was found between feed efficiency $(F: G)$ and time at the feeder. Shabi et al. (2005) found a positive correlation between milk yield and eating duration and a small correlation with milk yield and feed intake. No correlation was found between number of visits and milk yield.

In 2007, Haddad and Obeidat compared Awassi lambs with Baladi kids. They found that lambs consumed more dry and organic matter; however, kids had a better digestibility. Lambs had a higher final weight and ADG compared to kids, although kids had a more desirable $\mathrm{F}$ : $\mathrm{G}$ ratio. No difference was seen in eating or ruminating times; however, lambs had a faster eating rate. Time spent chewing was similar for lambs and kids. Kids were more efficient at utilizing energy possibly due to better digestibility of 
feed; however, kids may have spent more time in energy expensive behaviors resulting in a lower ADG.

Low RFI pigs visit the feeder less frequently than high RFI by spreading their visits over the entire day (de Haer et al., 1993). More efficient pigs will therefore eat more per visit and spend less time eating. Also, de Haer et al. reported a positive correlation between eating rate and backfat thickness and growth. A leaner animal eats slowly in small meals. Rauw et al. (2006b) reported that barrows that remained at the feeder longer ate more and were less efficient; however, feeding frequency was not related to the amount of time each animal spent eating. Feeding frequency and feed intake were not correlated. Less efficient barrows consumed more feed over the study. Differences will be seen with variation in stocking rate, breed, sex, age, and feeding methods. Rauw et al. (2006a) found that pigs with a higher eating rate grew faster; however, there was no difference in RFI. Feeding rate increased linearly with age at 0.47 $\mathrm{g} / \mathrm{min} / \mathrm{kg}$ gain in body weight.

Nkrumah et al. (2007) reported breed differences for feeding frequency. Charolais had more visits than Angus or crossbred cattle, while feeding duration and amount of time the head was lowered were not different. They found that duration of feeding and time the head was lowered were phenotypically and genetically correlated with RFI and FI. Amount of time eating was positively correlated with marbling score, ADG, ultrasound back fat thickness, and body weight. A negative correlation was seen with ADG and flight speed. In 2006, Nkrumah et al. found that the longer animals ate, more methane was produced, while retained and metabolizable energy decreased. 
Single born rams consumed more feed per visit and daily when compared to multiple birth rams (Cammack et al., 2005). The multiple birth rams had a higher frequency of feeder visits than single born rams. Rams produced by older dams consumed more daily and per visit compared to rams born to 1-year old dams. No relationship was seen with RFI and age of dam or birth number. They found that rams with higher frequency of visits have a higher feed intake and ADG.

Golden et al. (2008) found that more efficient steers consumed less during fewer visits to the feed supply. Positive RFI steer have less consistent eating patterns. Golden et al. reported no differences in eating rate or growth of positive and negative RFI steers except during one period, which was between 0300 and 0600 . Steers had the highest eating rates during the day. With differences in RFI and feeding behaviors in bucks, rams, and bulls, we investigated the three species to determine if relationships occurred.

\section{REFERENCES}

Abijaoudé, J. A., P. Morand-Fehr, J. Tessier, P. Schmidely, and D. Sauvant. 2000. Diet effect on the daily feeding behaviour, frequency and characteristics of meals in dairy goats. Livestock Prod. Sci. 64:29-37.

Allcroft, D. J., B. J. Tolkamp, C. A. Glasbey, and I. Kyriazakis. 2004. The importance of 'memory' in statistical models for animal feeding behaviour. Behavioural Processes 67:99-109.

Archer, J. A., P. F. Arthur, R. M. Herd, P. F. Parnell, and W. S. Pitchford. 1997. Optimum Postweaning Test for Measurement of Growth Rate, Feed Intake, and Feed Efficiency in British Breed Cattle. J. Anim. Sci. 75:2024-2032. 
Arthur, P. F., J. A. Archer, D. J. Johnston, R. M. Herd, E. C. Richardson, and P. F. Parnell. 2001. Genetic and phenotypic variance and covariance components for feed intake, feed efficiency, and other postweaning traits in Angus cattle. J. Anim. Sci. 79:2805-2811.

Arthur, P. F., R. M. Herd, J. Wright, G. Xu, K. Dibley, and E. C. Richardson. 1996. Net feed conversion efficiency and its relationship with other traits in beef cattle. Proc. Aust. Soc. Anim. Prod. 21:107-110.

Baker, S. D., J. I. Szasz, T. A. Klein, P. S. Kuber, C. W. Hunt, J. B. Glaze Jr., D. Falk, R. Richard, J. C. Miller, R. A. Battaglia, and R. A. Hill. 2006. Residual feed intake of purebred Angus steers: Effects on meat quality and palatability. J. Anim. Sci. 84:938-945.

Basarab, J. A., M. A. Price, J. L. Aalhus, E. K. Okine, W. M. Snelling, and K. L. Lyle. 2003. Residual feed intake and body composition in young growing cattle. Can. J. Anim. Sci. 83:189-204.

Brouns, F. and S. Edwards. 1994. Social rank and feeding behaviour of group-housed sows fed competitively or ad libitum. Appl. Anim. Behav. Sci. 39:225-235.

Cammack, K. M., K. A. Leymaster, T. G. Jenkins, and M. K. Nielsen. 2005. Estimates of genetic parameters for feed intake, feeding behavior, and daily gain in composite ram lambs. J. Anim. Sci. 83:777-785.

Castro Bulle, F. C. P., P. V. Paulino, A. C. Sanches, and R. D. Sainz. 2007. Growth, carcass quality, and protein and energy metabolism in beef cattle with different growth potentials and residual feed intakes. J. Anim. Sci. 85:928-936.

De Haer, L. C. M., P. Luiting, H. L. M. Aarts. 1993. Relations among individual 
(residual) feed intake, growth performance and feed intake pattern of growing pigs in group housing. Livest. Prod. Sci. 36:233-253.

Georgsson, L. and J. Svendsen. 2002. Degree of competition at feeding differentially affects behavior and performance of group-housed growing-finishing pigs of different relative weights. J. Anim. Sci. 80:376-383.

Golden, J. W., M. S. Kerley, and W. H. Kolath. 2008. The relationship of feeding behavior to residual feed intake in crossbred Angus steers fed traditional and noroughage diets. J. Anim. Sci. 86:180-186.

Haddad, S. G. and B. S. Obeidat. 2007. Production efficiency and feeding behavior of Awassi lambs and Baladi kids fed on a high concentrate diet. Small Ruminant Res. 69:23-27.

Hamel, S. and S. D. Côté. 2008. Trade-offs in activity budget in an alpine ungulate: contrasting lactating and nonlactating females. Anim. Behav. 75:217-227.

Kriese, L. A., J. K. Bertrand, and L. L. Benyshek. 1991. Age adjustment factors, heritabilities and genetic correlations for scrotal circumference and related growth traits in Hereford and Brangus bulls. J. Anim. Sci. 69:478-489.

Langhans, W., M. Senn, E. Scharrer, and E. Eggenberger. 1988. Free-feeding pattern of pygmy goats eating a pelleted diet. J. Anim. Physiol. a. Anim. Nutr. 59:160-166.

Luiting, P., J. W. Schrama, W. v. d. Hel, E. M. Urff. 1991. Metabolic differences between White Leghorns selected for high and low residual food consumption. Br. Poult. Sci. 32:763-782.

Manninen, M., R. Sormunen-Cristian, L. Jauhiainen, S. Sankari, and T. Soveri. 2006. 
Effects of feeding frequency on the performance and welfare of mature Hereford cows and their progeny. Livestock Sci. 100:203-215.

Morand-Fehr, P., E. Owen, and S. Giger-Reverdin. 1991. Feeding behaviour of goats at the trough. In: Goat Nutrition. EAAP, Wageningen. pp3-12.

Mousel, M. R., W. W. Stroup, and M. K. Nielsen. 2001. Locomotor activity, core body temperature, and circadian rhythms in mice selected for high and low heat loss. J. Anim. Sci. 79:861-868.

Nguyen, N. H., C. P. McPhee, and C. M. Wade. 2005. Responses in residual feed intake in lines of Large White pigs selected for growth rate on restricted feeding (measured on ad libitum individual feeding). J. Anim. Breed. Genet. 122:264-270.

Nielson, M. K., B. A. Freking, L. D. Jones, S. M. Nelson, T. L. Vorderstrasse, and B. A. Hussey. 1997. Divergent selection for heat loss in mice: II. Correlated responses in feed intake, body mass, body composition, and number born through fifteen generations. J. Anim. Sci. 75:1469-1476.

Nkrumah, J. D., D. H. Crews Jr., J. A. Basarab, M. A. Price, E. K. Okine, Z. Wang, C. Li, and S. S. Moore. 2007. Genetic and phenotypic relationships of feeding behavior and temperament with performance, feed efficiency, ultrasound, and carcass merit of beef cattle. J. Anim. Sci. 85:2382-2390.

Nkrumah, J. D., E. K. Okine, G. W. Mathison, K. Schmid, C. Li, J. A. Basarab, M. A. Price, Z. Wang, and S. S. Moore. 2006. Relationships of feedlot feed efficiency, performance, and feeding behavior with metabolic rate, methane production, and energy partitioning in beef cattle. J. Anim. Sci. 84:145-153.

Olofsson, J. 1999. Competition for total mixed diets fed for ad libitum intake using one or 
four cows per feeding station. J. Dairy Sci. 82:69-79.

Orr, R. J., P. D. Penning, S. M. Rutter, R. A. Champion, A. Harvey, A. J. Rook. 2001. Intake rate during meals and meal duration for sheep in different hunger states, grazing grass or white clover swards. Appl. Anim. Behav. Sci. 75:33-45.

Pfister, J. A., J. C. Malechek, and D. F. Balph. 1988. Foraging behaviour of goats and sheep in the Caatinga of Brazil. J. Appl. Ecol. 25:379-388.

Ramli, M. N., M. Higashi, Y. Imura, K. Takayama, and Y. Nakanishi. 2005. Growth, feed efficiency, behaviour, carcass characteristics and meat quality of goats fed fermented Bagasse feed. Asian-Aust. J. Anim. Sci. 18:1594-1599.

Rauw, W. M., J. Soler, J. Tibau, J. Reixach, and L. Gomez Raya. 2006a. Feeding time and feeding rate and its relationship with feed intake, feed efficiency, growth rate, and rate of fat deposition in growing Duroc barrows. J. Anim. Sci. 84:3404-3409.

Rauw, W. M., J. Soler, J. Tibau, J. Reixach, and L. Gomez Raya. 2006b. The relationship between residual feed intake and feed intake behavior in group-housed Duroc barrows. J. Anim. Sci. 84:956-962.

Richardson, E. C., R. M. Herd, V. H. Oddy, J. M. Thompson, J. A. Archer, and P. F. Arthur. 2001. Body composition and implications for heat production of Angus steer progeny of parents selected for and against residual feed intake. Australian J. Experimental Agriculture. 41:1065-1072.

Richardson, E. C., R. M. Herd, J. A. Archer, R. T. Woodgate, and P. F. Arthur. 1998. Steers bred for improved net feed efficiency eat less for the same feedlot performance. Anim. Prod. In Australia. 22:213-216.

Schenkel, F. S., S. P. Miller, and J. W. Wilton. 2004. Genetic parameters and breed 
differences for feed efficiency, growth, and body composition traits of young beef bulls. Can. J. Anim. Sci. 84:177-185.

Schwartzkopf-Genswein, K. S., S. Atwood, and T. A. McAllister. 2002. Relationships between bunk attendance, intake and performance of steers and heifers on varying feeding regimes. Appl. Anim. Behav. Sci. 76:179-188.

Shabi, Z., M. R. Murphy, and U. Moallem. 2005. Within-day feeding behavior of lactating dairy cows measured using a real-time control system. J. Dairy Sci. $88: 1848-1854$.

Snowder, G. D. and L. D. Van Vleck. 2003. Estimates of genetic parameters and selection strategies to improve the economic efficiency of postweaning growth in lambs. J. Anim. Sci. 81:2704-2713.

Solanki, G. S. 1994. Feeding habits and grazing behavior of goats in a semi-arid region of India. Small Ruminant Research. 14:39-43.

Tolkamp, B. J., D. J. Allcroft, E. J. Austin, B. L. Nielsen, and I. Kyriazakis. 1998. Satiety splits feeding behaviour into bouts. J. Theor. Biol. 194:235-250.

Tolkamp, B. J., D. P. N. Schweitzer, and I. Kyriazakis. 2000. The biologically relevant unit for the analysis of short-term feeding behavior of dairy cows. J. Dairy Sci. 83:2057-2068

Van, D. T. T., I. Ledin, and N. T. Mui. 2002. Feed intake and behaviour of kids and lambs fed sugar cane as the sole roughage with or without concentrate. Anim. Feed Sci. and Tech. 100:79-91.

Wang, Z., J. D. Nkrumah, C. Li, J. A. Basarab, L. A. Goonewardene, E. K. Okine, D. H. 
Crews Jr., and S. S. Moore. 2006. Test duration for growth, feed intake, and feed efficiency in beef cattle using the GrowSafe System. J. Anim. Sci. 84:2289-2298. 
Chapter 1-Bucks 


\section{ABSTRACT}

Our objective was to investigate feeding behaviors associated with common production measurements including residual feed intake (RFI) and average daily gain (ADG). Twenty-eight three month old Boer buck $(21.4 \mathrm{~kg})$ crosses were housed together in a partially covered $14.6 \times 51.2 \mathrm{~m}$ pen during the summer of 2006 . Using radio frequency technology (GrowSafe systems Ltd), behavioral intake data were collected for 53 days. Bucks were fed a commercially available pelleted ration provided ad libitum. Feed was offered via two modified GrowSafe feed nodes (A and B) adjacent to one another in the front center of the pen. Feeding behaviors were analyzed using the GLM, TTEST and FREQ procedures of SAS. Variables investigated were events (any visit to the feeder), feed intake per feeding event, event time, event duration, feeding location preference, leg circumference, birth number, ADG, and RFI. On average, goats gained $0.32 \mathrm{~kg} / \mathrm{d}$ with no association detected with RFI. Goats with negative RFI values had fewer feeding events than positive RFI goats $(P<0.001)$ and less non-feeding events $(P$ $<0.001)$. No difference was seen between positive and negative RFI with leg circumference, back fat thickness and loin area. Goats had a preference towards eating at node $\mathrm{B}$ (closest to the open end of the barn) over node $\mathrm{A}$ at all times of the day $(16,300$ vs. 11,926 \# of events; $P<0.01)$. The mean time for feeding event at node A was greater than B $(77.3 \pm 1.4$ vs. $70.5 \pm 1.2 \mathrm{~s} ; P<0.01)$. More non-feeding events occurred during the daylight hours than during the night $(5,155$ vs. 2,$444 ; P<0.01)$. Twenty-one percent of the visits resulted in no feed consumption. The majority of feeding events occur with less than $113.5 \mathrm{~g}$ consumed rather than greater than $113.5 \mathrm{~g}$, excluding non-feeding events $(23,987$ vs. 4,$239 ; P<0.01)$. These events occur predominantly between 0600 and 
2100 with most occurring between 1600 and 2100. Most non-feeding events also occurred at similar times. However, the largest meals (over $454 \mathrm{~g}$ ) occur between 0600 and 1100 . Thus, the majority of small meals occur in early evening while larger meals occur in the morning. In conclusion, there appear to be little identifiable relationships between feeding behavior and most common production traits including residual feed intake in crossbred meat-type bucks of predominantly Boer lineage.

Key words: behavior, goats, intake, residual feed intake

\section{INTRODUCTION}

With feed costs as a major expense, animals with a negative residual feed intake (RFI) can utilize feed more efficiently and would be more favorable as long as production was maintained or no negative traits were associated with RFI. Animals will have slightly different metabolic requirements from others of the same species in a similar environment due to genetic differences. It is believed that these are the differences for which we are selecting for when utilizing RFI as a selection criterion. In addition, certain animal behaviors will cause an animal to expend higher amounts of energy and require a higher intake to have similar gains in weight. Feed intake and growth rate have an estimated 25\% genetic variation (Cammack et al, 2005). Thus, many other factors have a role in maintenance and growth as well. With multiple factors influencing maintenance, growth and weight gain in animals, behavioral variability may have a large role in affecting efficiency and performance. Feeding behaviors are important in the dairy industry for increased milk yield and improved estrus detection, while it is important in 
the beef, sheep and goat industry for increased meat production. Increasing positive behaviors and decreasing negative behaviors will result in better productivity (Abijaoudé et al., 2000).

Behavior variables may affect common production measurements; therefore, visual assessment of animal behavior may decrease the amount of production testing of growing animals. Each animal will have social influences affecting daily intake, meal size, feeding time, duration, frequency and possibly location preference. Thus, the objective of this study was to determine how behavioral factors in group-housed goats influence common production traits, feed intake, ADG and RFI.

\section{MATERIALS AND METHODS}

All goats used in this study were managed similar to the previous ram studies. Twenty-eight Boer buck crosses ( $89.68 \pm 3.83$ days of age) were housed together in a $14.6 \mathrm{~m} \times 51.2 \mathrm{~m}$ pen, where $156.2 \mathrm{~m}^{2}$ was under roof. Data were collected for 53 days from July to September 2006 at the Reymann Memorial Farm, Wardensville, WV. Animals were fed a commercially available pelleted ration provided ad libitum in two feeding stations adjacent to one another in the front center of the pen. The chemical composition of the ration was as follows: $22.0 \%$ crude fiber, $16.0 \%$ crude protein, $6.3 \%$ ash, and $2.9 \%$ crude fat. With 4 Growsafe (Growsafe Systems Ltd) feed nodes in the pen, only the two inner nodes (A and B) were used for feed and data collection, while the goats were denied access to the other two. Modifications were made to the feed system to prevent more than one animal from accessing feed at one time (Figure 1). Kane ${ }^{\circledR}$ nursery 
feeders $(61 \times 22 \times 61 \mathrm{~cm})$ were placed within the feed node with solid plywood fronts attached to the front of the nodes to limit access to one animal (Figure 2).

Behavioral data were collected using Growsafe software and radio frequency technology. Allflex ${ }^{\circledR}$ transponders were placed in each bucks left ear. Animal identification number, time and date of observation, scale location, duration of feeding event, time the animal's head was lowered, and amount of feed displaced were recorded. Individual goats were weighed weekly. Residual feed intake and average daily gain were calculated for each animal using regression analysis. Metabolic midweight was calculated similar to Archer and Pitchford (1996).

While on the study, additional production measurements were taken. Leg circumference was measured as an indicator of muscle mass. Body condition score was assigned by two independent evaluators and averaged. Scores were determined based on visual observation of body conformation and muscling. Final body weight was measured and ADG was calculated for the duration of the study. Back fat thickness and loin eye area (LEA) were measured using ultrasonography. Measurements were collected in front of the last rib with two cross-sectional images. Adjusted LEA, leg circumference and fat thickness measurements were determined with an adjusted body weight of $36.56 \mathrm{~kg}$.

Activity at the bunk was recorded as visits by the GrowSafe ${ }^{\circledR}$ equipment. A feeding event is one where feed is consumed, while a non-feeding event occurs when the animal visits the feeder and no feed is consumed. Feeding bouts were used rather than meal periods for the analyses. Meal sizes at each event were separated into 5 categories: 0 g, 0-113.5 g, 113.5-227 g, 227-454 g and $>454 \mathrm{~g}$ feed consumed. These meal sizes were similar to those of Cammack et al. (2005) in ram lambs. If no feed was consumed this 
was considered a non-feeding event. Time of day was divided into 5 categories: 0000 0600, 0600-1100, 1100-1600, 1600-2100, and 2100-2400. Day and night were defined as 0700-1900 and 1900-0700, respectively. Eating rates were calculated for each feeding bout (amount feed consumed/duration at feed bunk).

Six of the goats were removed from the analyses: five had missing observations and one died. The data for the first two days and final seven days were removed because all four scales were in use at those times. Four other days were removed during the study due to insufficient data collection on those days. All non-positive feeding events, such as wind and external forces, were deleted. A total of 35,825 observations were used in the analysis.

Feeding behaviors were analyzed using the GLM, TTEST and FREQ procedures of SAS. Mean values were used for daily feed intake and event feed intake when relating data to ADG and RFI. Data was considered significant when $P<0.05$.

\section{RESULTS AND DISCUSSION}

Daily variation was seen for feeding event durations and amount consumed (Figure 3) for each animal $(P<0.01)$. As expected, each goat consumed different amounts of feed and with different frequencies of feeding bouts per day. This variation could be from internal regulation of intake, environmental factors or other animals. Drinking behavior was not monitored in this study; however, animals may drink during meals and leave the feeder for a short duration and return after a draft; therefore, drinking may have increased the number of feeding events that occurred. Rossi et al. (1998) found that $60 \%$ of meals in pygmy goats were not associated with drinking, so drinking was not 
the only reason for variation in feeding event duration and number. The number of feeding bouts would change when the animal left the feeder for water, but may not change the overall meal size if he returned to feed.

There was no difference between initial or final body weight in negative and positive RFI goats (Table 1), and no relationship was seen between RFI and ADG. With a similar ADG between the two groups, the final weight should be similar between the two. Similar results were seen in genetic correlations in ram lambs (Cammack et al, 2005), beef steers (Castro Bulle et al, 2007), and beef bulls (Felton et al., 2008) when comparing ADG and RFI. There were no relationships between positive and negative RFI goats with leg circumference or birth number (Table 2). Furthermore, no difference was seen with RFI and measurements adjusted for body weight (leg circumference, back fat thickness, LEA).

No difference was found when comparing birth number in the goats for ADFI, RFI, ADG, meal size, or leg circumference (Table 3). However, in ram lambs it was reported that single birth lambs had a larger feeding event intake than twins or triplets (Cammack, 2005). Rauw et al. (2000) reported a higher RFI in mice bred for large litter sizes. This was not seen in our study; however, the single birth bucks tended to have a larger LEA $(P<0.08)$. Positive RFI goats had many more feeding bouts than negative RFI goats $(P<0.001)$. Golden et al. (2008) reported similar findings in Angus steers.

The majority of the feeding events occurred during the daylight hours (Table 4). Goats consumed more food during visits at night $(P<0.001)$ with a higher eating rate $(P$ $<0.001$ ) than during the day (Table 5). Langhans et al. (1988) reported that pygmy goats consume approximately $63 \%$ of their meals during the light hours of the day. The 
increased number of feeding bouts during the night may have been from subordinate animals. The majority of these feeding events (33\%) occurred between 1600-2100. Goats consumed different amounts of feed $(P<0.05)$ over different durations per time period (Table 6). Orr et al. (2001) reported that the main meal in sheep occurs between 18001900 when grazing on grass and clover. Fewer non-feeding events occurred at night as well $(P<0.01)$, which may have been from fewer forced departures from the scale. Many subordinate animals will alter their feeding behaviors and eat during the night when dominant animals are resting to receive adequate energy (Brouns and Edwards, 1994). Subordinate animals also improve efficiency when feed is a limited resource to better utilize nutrients. There was no difference between positive and negative RFI goats with the time of day the feed was consumed. Eating rates were not different between negative and positive RFI animals. In beef steers, Golden et al. (2008) found one time period out of sixteen in two experiments when a difference in eating rates occurred between efficient and inefficient steers. They did find that eating rates are higher during the day than at night. In this study, the goats ate either slowly or very quickly during the day and night, respectively.

Abijoudé et al. (2000) determined that Alpine and Saanen dairy goats in midlactation will consume around $60 \%$ of their daily intake during two main meals. Goats, sheep and cattle consume two large or main meals per day and consume several secondary or smaller meals throughout the day. The young bucks in this study had more feeding events between 0600-1100 and 1600-2100 which may be when the two main meals were consumed. The additional feeding events would be the secondary meals. 
Positive RFI goats had a larger ADFI than negative RFI animals $(P<0.001)$. Rauw et al. (2006a) had similar findings in Duroc barrows suggesting that high daily intake resulted in positive RFI rather than a high feed intake activity. The positive RFI group had a larger number of observations including both feeding and non-feeding visits to the trough.

The goats in our study spent more time feeding at scale B than at scale A $(P<$ 0.01) (Table 7); however, the amount of time spent at scale A was greater than scale B ( $P$ $<0.01$ ). Brouns and Edwards (1994) noted that dominant pigs were more likely to eat out of the feed bunk on the right, while submissive pigs were more likely to eat from the two feed bunks to the center and left side. They found this for both total duration and feeding bout length. This may not have been a dominance issue in the goats, but more of a social grouping with feedings. Goats will gather in social hierarchies for feeding and remain in these groups for drinking, ruminating, and idling (Shinde et al, 2004).

After completion and analysis of data, some care should be taken in interpretation of behavioral data collected in similar manners. Feeding behavior in these goats may have been skewed since only one animal can feed at a time with 2 feeding locations. Use of multiple feed nodes may have provided more accurate data on the goat feeding behavior due to their flocking instinct. Although dominance behaviors were not monitored during the sire performance testing, social interactions with displacements from the feeder may have influenced the amount of time a goat would have spent feeding.

In conclusion, as seen in other species, negative RFI goats consume less daily in fewer feeding bouts with similar gains in body mass. Goats have a preference to location of feeding and have many small feeding bouts rather than large ones. Feeding bouts occur 
primarily between 0600-1100 and 1600-2100. Production measurements between negative and positive RFI goats are not different when looking at leg circumference, LEA and fat thickness; however, there is a trend for larger LEA and fat thickness in single birth bucks.

\section{LITERATURE CITED}

Abijoudé, J. A., P. Morand-Fehr, J. Tessier, P. Schmidely, and D. Sauvant. 2000. Diet effect on daily feeding behavior, frequency and characteristics of meals in dairy goats. Lives. Prod. Sci. 64:29-37.

Archer, J. A. and W. S. Pitchford. 1996. Phenotypic variation in residual feed intake of mice at different ages and its relationship with efficiency of growth, maintenance and body composition. Anim. Sci. 63:149-157.

Brouns, F., and S. Edwards.1994. Social rank and feeding behaviour of group-housed sows fed competitively or ad libitum. Appl. Anim. Behav. Sci. 39:225-235.

Cammack, K. M., K. A. Leymaster, T. G. Jenkins, and M. K. Nielsen. 2005. Estimates of genetic parameters for feed intake, feeding behavior, and daily gain in composite ram lambs. J. Anim. Sci. 83:777-785.

Castro Bulle, F. C. P., P. V. Paulino, A. C. Sanches, and R. D. Sainz. 2007. Growth, carcass quality, and protein and energy metabolism in beef cattle with different growth potentials and residual feed intakes. J. Anim. Sci. 85:928-936.

Felton, E. E. D., J. A. Gulas, and J. E. Warren. 2008. Residual feed intake as a measure of feed efficiency of beef bulls in a test station. (Submitted to J. Anim. Sci. April 2008). 
Golden, J. W., M. S. Kerley, and W. H. Kolath. 2008. The relationship of feeding behavior to residual feed intake in crossbred Angus steers fed traditional and no roughage diets. J. Anim. Sci. 86:10-186.

Langhans, W., M. Senn, E. Scharrer, and E. Eggenberger. 1988. Free-feeding pattern of pygmy goats eating a pelleted diet. J. Anim. Physiol. and Anim. Nutr. 59:160166.

Orr, R. J., P. D. Penning, S. M. Rutter, R. A. Champion, A. Harvey, and A. J. Rook. 2001. Intake rate during meals and meal duration for sheep in different hunger states, grazing grass or white clover swards. Appl. Anim. Behav. Sci. 75:33-45.

Rauw, W. M., P. Luiting, M. W. A. Verstegen, O. Vangen, and P. W. Knap. 2000. Differences in food resource allocation in a long-term selection experiment for litter size in mice. II. Developmental trends in body weight against food intake. Anim. Sci. 71:39-47.

Rauw, W. M., J. Soler, J. Tibau, J. Reixach, and L. Gomez Raya. 2006a. Feeding time and feeding rate and its relationship with feed intake, feed efficiency, growth rate, and rate of fat deposition in growing Duroc barrows. J. Anim. Sci. 84: 3404-3409.

Rauw, W. M., J. Soler, J. Tibau, J. Reixach, and L. Gomez Raya. 2006b. The relationship between residual feed intake and feed intake behavior in group-housed Duroc barrows. J. Anim. Sci. 84: 956-962.

Rossi, R., E. Del Prete, J. Rokitzky, and E. Sharrer. 1998. Effects of a high $\mathrm{NaCl}$ diet on eating and drinking patterns in pygmy goats. Physiol. and Behav. 63:601-604.

Shinde, A., D. Verma, and N. Singh. 2004. Social dominance-subordinate relationship in a flock of Marwari goats. Indian J. Anim. Sci. 74:216-219. 
Chapter 2-Rams 


\section{ABSTRACT}

Data from two consecutive years of performance testing young rams in an evaluation program were utilized to investigate any potential relationship between commn production traits and measure behavioral activity. The objective of this investigation was identify measurable behavioral traits associated with common performance measurements used in a ram test. The first year included 37 rams of Dorset, Suffolk or Khatadin breeding and 44 rams of Dorset or Suffolk breeding in the second year. Using GrowSafe (GrowSafe Systems Ltd) technology, behavioral intake data were collected for 60 and 64 days, respectively. Rams were fed a pelleted ration provided ad libitum. Rams were randomly divided into two pens each year. In year one, the rams had access to one GrowSafe feed node per pen, while the second year they had access to two nodes per pen. Feed intake, number of visits, feeding events, non-feeding events, feeding location, residual feed intake (RFI), average daily gain (ADG), scrotal circumference (SC), loin eye area (LEA) and fat thickness were examined. Negative RFI animals consumed less feed $(P<0.01)$ than positive animals. In the first year, negative RFI rams had fewer visits $(P<0.01)$, less feeding events $(P<0.01)$, less non-feeding events $(P<$ $0.05)$ and a faster eating rate $(P<0.01)$. These differences were not seen with RFI in the second year. In the first year, single born rams were older $(P<0.01)$, had a larger SC $(P$ $<0.01)$, initial and final weight $(P<0.01)$, fat thickness $(P<0.01)$ and LEA $(P<0.01)$. In the second year, single born rams had higher initial and final weights $(P<0.01)$ and tended to have a larger SC $(P=0.07)$ and LEA $(P=0.06)$. During both years, $70 \%$ of feeding events occurred during day. Most feeding bouts were during the day with less than $113.5 \mathrm{~g}$ consumed $(P<0.01)$. With limited differences between RFI and 
performance measurements in young rams, activity level and social behaviors may be more important to monitor than feeding frequency behaviors. In conclusion, RFI appears to have limited relationships with behavior.

Key words: behavior, rams, intake, residual feed intake

\section{INTRODUCTION}

As the sheep industry continues to improve methods for evaluating rams, research has focused on several common production measurements to determine maximal gains per animal. Many traits are important for the value of an animal and are regarded as determinants to either breed or cull an animal. The ram test has been designed to look at growth traits for both purebred and crossbred rams by evaluating rams under similar conditions to determine which animals are of superior quality and therefore should be used for breeding.

Animal efficiency is important to lower feed costs by culling animals that are expensive to raise yet produce similar yields to other animals. Residual feed intake is becoming the preferred measurement to determine negative or high efficiency against positive or low efficiency animals. Growth is a factor of efficiency measured by weight gained in feed conversion ratios. Using radio frequency technology, monitoring individual animal intake has become easier and evaluating individual animal efficiency has become more practical. However, considerable time and cost are still required to obtain accurate measures of efficiency. Thus, the objective of the investigation was to use radio frequency technology to compare feeding behaviors with common performance 
measurements associated with ram tests and feed efficiency to determine if observational data could be used as indicators f efficiency and expected performance.

\section{MATERIALS AND METHODS}

The Animal Care and Use Committee Guidelines of West Virginia University were followed for management of all rams used in the study. For the first year of the study, 37 West Virginia University owned rams were randomly divided into two groups. The groups were housed in adjacent pens (I and II) that were $14.6 \mathrm{~m}$ x $51.2 \mathrm{~m}$, where $156.2 \mathrm{~m}^{2}$ were under roof. Pen I had 19 rams while pen II had 18. The rams were Dorset, Suffolk or Khatadin breeds and were born at either the West Virginia University Livestock Farm in Morgantown, WV or Reymann Memorial Farm located in Wardensville, WV. All performance testing occurred at the Reymann Memorial Farm at the young sire testing facility. Rams were fed a pelleted ration (Table 8) provided ad libitum in one feeding station at the front center of each pen. Two GrowSafe (GrowSafe Systems Ltd) feed nodes were located in each pen (A and B in pen I and C and D in pen II); however, only one node was used for feed and data collection per pen. The feeding system was modified to prevent more than one animal from accessing feed at one time, which included a Kane nursery feeder $(61 \times 22 \times 61 \mathrm{~cm})$ placed within the feed node with solid plywood fronts attached to the front of the nodes with openings adjusted so that only one animal could gain entry at a time. In year two of the study, 44 rams were randomly divided into two groups in similar pens. The rams were either Dorset or Suffolk breeds and were consigned from several different private and university farms. Two GrowSafe feed nodes were located in each pen, with both nodes active for feed and data 
collection. The same modifications were used to prevent multiple animals from feeding at one time. The studies occurred from May to July of 2005 and 2006.

Rams were vaccinated for Enterotoxemia, Soremouth and Tetanus prior to the commencement of the study and treated for internal and external parasites. Lambs were examined by a veterinarian for soundness and health.

Allflex ${ }^{\circledR}$ transponders were used with GrowSafe radio frequency technology to record feeding behavior data. Transponders were located in each animal's left ear. Radio frequency technology recorded animal identification, time spent at feed node, time animal's head was lowered, amount of feed displaced, and feed node location. ADG was calculated using initial, intermittent, and the final weights. ADG used for calculations was the ADG for the total length of the study. Residual feed intake was calculated with regression analysis (Figure 4) according to Archer and Pitchford (1996).

Ultrasound measurements were taken to measure fat thickness and LEA. The measurements were collected from images taken between the $12^{\text {th }}$ and $13^{\text {th }}$ ribs. Ten of the rams were randomly selected and sacrificed to verify ultrasound data during the first year. Scrotal circumference (SC) was also measured on the last day of the study. LEA and fat thickness were calculated with an adjusted body weight of $56.82 \mathrm{~kg}$ to compare actual and adjusted measurements.

Data collected through radio frequency technology occurred with each observation as a visit. Not all visits resulted in feed consumption; therefore, the observations were divided into feeding events and non-feeding events or bouts. Feeding bouts are not considered meals because any distraction that would cause the animal to remove his head from the feed node would begin a new event. Feeding bouts were 
divided into 5 categories similar to Cammack et al. (2005): $0 \mathrm{~g}, 0-113.5 \mathrm{~g}, 113.5-227 \mathrm{~g}$, 227-454 g, and $>454 \mathrm{~g}$ feed consumed. Time periods were divided by hour into 5 categories and also divided into 2 periods for day and night. Day and night periods were divided as follows: 0600-2100 for day and 2100-0600 for night. The five periods for meal consumption were 0000-0600, 0600-1100, 1100-1600, 1600-2100 and 2100-2400. The mean eating rate was calculated for each ram for all feeding events (amount feed consumed/time at feeder).

Behavioral data were analyzed using the GLM, FREQ and TTEST procedures of SAS (SAS Institute Inc., Cary, NC). Performance data were analyzed with the TTEST procedure. Significance was determined at $P<0.05$.

\section{RESULTS}

Year 1

Performance means for positive and negative RFI rams are reported (Table 9). No difference was seen in age, birth weight, and initial or final test weight between positive and negative RFI rams. Negative RFI rams consumed less feed per day $(P<0.01)$ (Figure 5), and had fewer visits $(P=<0.01)$, feeding bouts $(P<0.01)$ and non-feeding bouts $(P=$ 0.02) when compared to positive RFI rams. There was no difference in ADG between positive and negative RFI rams. Negative RFI rams had a higher $(P<0.01)$ eating rate than positive RFI rams. There was no difference between positive and negative RFI rams with SC, back fat thickness, LEA, adjusted back fat thickness and adjusted LEA.

No difference was seen in birth weight for single born rams and twins or triplets; however, single born rams on average, were older $(P<0.01)$ at the start of the study 
(Table 10). Single born rams were heavier at the start $(P<0.01)$ and finish $(P<0.01)$ of the study. Single born rams tended to have a higher ADG $(P<0.08)$. Birth number did not affect RFI, mean intake or number of feeding events; however, single born rams had a larger scrotal circumference $(P<0.01)$, higher back fat thickness $(P<0.01)$ and LEA $(P<0.01)$

Older rams had a larger frame size compared to younger rams $(P<0.01)$. Frame size did not influence RFI, mean intake, eating rate or number of feeding events, while small framed rams tended to have a higher ADG $(P=0.10)$, but large framed rams had more non-feeding bouts $(P=0.04)$. Large framed rams were heavier $(P<0.01)$ at the start and conclusion of the study. Larger framed rams had a larger SC $(P<0.01)$, higher back fat thickness $(P<0.01)$ and larger LEA $(P<0.01)$.

Year 2

Similar to year 1, no difference was seen between RFI and ADG, age, or initial and final body weights. Daily intake was quite various across rams (Figure 6). Average daily intake was lower for negative RFI rams (Figure 7). Eating rate, visits, feeding bouts, and non-feeding bouts were not affected by RFI. Positive RFI rams ate more feed per day $(P<0.01)$. There was no difference in muscle score, SC, rump fat thickness and LEA for positive and negative RFI rams; however, positive RFI rams had a higher structure score than negative rams $(P=0.03)$.

Neither age, ADG, RFI, nor mean intake per ram were affected by birth number. Single born rams did have a higher initial $(P<0.001)$ and final $(P<0.001)$ body weight. There was no difference in the number of feeding and non-feeding bouts, or eating rate 
when comparing birth number. Futhermore, when comparing birth number, no difference was seen in muscle score, structure score, or rump fat thickness. Single birth rams tended to have a larger SC $(P=0.07)$ and LEA $(P=0.06)$.

Rams with a large frame size were older than small frame rams $(P<0.01)$ and tended to have a faster eating rate $(P=0.07)$. Rams with a large frame had a higher muscle score $(P<0.05)$, but a lower structure score $(P<0.05)$. There were no differences in body weight, ADG, RFI, ADFI, fat thickness, or LEA as affected by frame size.

In year 2, due to known breed composition, breed effects were investigated (Table 11). Dorset rams were older than the Suffolk $(P<0.01)$ at the beginning of the study but there was no difference in RFI between breeds; however, Suffolk rams had a higher ADG $(P=0.05)$ and a tendency for more feeding events $(P=0.09)$. There was no difference between breeds initially; however, Suffolk rams weighed more at the conclusion of the study $(P<0.05)$. Dorset rams had a higher muscle score $(P<0.001)$, but Suffolk rams had a higher structure score $(P=0.002)$ and LEA $(P=0.003)$.

Behavioral data

In the second year, the rams preferred eating from scale B $55.75 \%$ of the time in pen 1, while in pen 2, the rams preferred to eat from scale C $54.85 \%$ of the time. Most feeding bouts occurred during daylight hours $(P<0.001)$, which was between 0600 and 2100. Seventy percent of the feeding bouts occurred during the daylight hours in both pens. Most of the feeding bouts occurred during the daylight hours with less than $113.5 \mathrm{~g}$ consumed $(P<0.01)$. During the first year, over $50 \%$ of the feeding bouts were during the day with less than $113.5 \mathrm{~g}$ consumed, while it was only $39 \%$ during the second year. 
In the first year, rams consumed more during feeding events in the day $(P<0.001)$ with a higher eating rate $(P<0.01)$ than at night (Table 12). In the second year, rams had longer daytime visit durations $(P<0.01)$ with more feed consumed per event $(P<0.01)$ at a higher eating rate $(P<0.01)$ than at night (Table 13). Rams consumed the most per feeding bout between 1100-1600 in year 1 (Table 14) and 11-2100 in year 2 (Table 15).

During the second half of the study in both years, rams had fewer visits but more feeding events with higher eating rates $(P<0.01)$. In the first half of year one, the rams had shorter feeding durations $(P<0.01)$ with a smaller amount of feed consumed per event $(P<0.01)$. During the second half of year two, rams spent the same amount of time at the scales but consumed more feed per event $(P<0.01)$.

\section{DISCUSSION}

The lengths of each study were 60 and 64 days for the two years. Each year had a prior acclimation period of two weeks to ensure rams would adjust to eating from the modified GrowSafe feeding scales. If rams did not consume food, they were removed prior to the study. This test length is similar to what was determined by Wang et al. (2006) for measuring RFI in beef bulls. Archer et al. (1997) had previously used a test date of 70 days for testing RFI in cattle; however, 35 days is ample for feed intake data.

No difference was seen between the age of ram lambs or the initial or final weights with RFI. Positive RFI rams consumed more food per day which is determined from the regression analysis; however, the positive RFI rams in the second year had as many feeding and non-feeding events as the negative RFI rams. Negative RFI rams would have fewer feeding events if they were eating the same amount of food during 
feeding bouts as the less efficient or positive RFI rams. The negative RFI rams did have fewer feeding events in the first year of the study. Golden et al. (2008) found that more efficient steers had fewer feeding bouts than inefficient steers.

Suffolk rams tended to have more feeding events than the Dorset rams. Rauw et al. (2006b) reported different numbers of feeding events in barrows of various breeds. They found that each breed appears to have a different frequency of feeding events. There was no relationship between ADG and RFI in either year. This result would be expected since previous research has found no relationship between RFI and ADG in rams (Cammack et al., 2005) or beef cattle (Nkrumah et al., 2006; Castro Bulle et al., 2007; Felton et al., 2008).

No difference was seen between RFI and scrotal circumference, LEA and rib fat in rams. Arthur et al. (2001) reported similar findings in Angus cattle for scrotal circumference; however, they found a small correlation with rib fat. Nguyen et al. (2005) found a similar correlation with backfat in swine. Arthur et al. (1996) found no relationship between RFI and scrotal circumference or loin-eye muscle area in beef cattle. No difference was detected with the body weight adjusted scores compared to the actual values when investigating production measurements. From this investigation, it was not necessary to adjust fat thickness or LEA to an average body weight.

In the first year of the study, the negative RFI rams had a higher eating rate than the positive RFI rams. There was no difference with RFI and eating rate in the second year. Golden et al. (2008) found no difference in eating rate between efficient and inefficient steers. Rauw et al. (2006a) reported that as pigs get older, their eating rate increases because of an increased body size; however, they found no relationship 
between RFI and eating rate. In the present study, rams had a higher eating rate the second half of the study while consuming more per feeding bout. The rams would have an increased body weight; however, they decreased their number of visits to the feeders. Orr et al. (2001) determined that eating rate decreases towards the end of a meal. When looking at feeding bouts, the eating rate would be slower when a meal was ending.

When comparing birth number with production measurements, single born rams had a larger SC and LEA in both years. In the first year of the study, the rams had thicker back fat. The increase in SC and LEA may be from the single birth rams being older in the first year; however, no difference in age was seen in the second year. The birth weights were not different for the single and multiple birth rams, although the single birth rams were heavier at the beginning and end of the study. In the first year of the study, the single birth rams tended to have a higher ADG. Mandal et al. (2003) found that the single birth lambs were different from multiple birth rams in all growth traits. Twins or triplets weighed less at birth and remained below single birth lambs till one year of age. They concluded that ADG was higher for single birth lambs at weaning; however, the ADG difference decreased till there was no difference at one year of age. Mandal et al. (2003) also determined that the growth efficiency was better for twins and triplets; however, there was no difference between RFI and birth number in either of the years.

The rams had no choice of feeding location in the first year of the study since they were limited to one feeding location. In the second year, the rams had a choice between two scales located adjacent to one another. Although they had a choice between feeding locations, the rams did not exhibit a preference. 
Although many feeding behaviors did not account for variation in RFI, more research should look at energy-expensive behaviors of positive and negative RFI rams along with dominance hierarchies. These additional behaviors may influence RFI more than feeding behaviors.

\section{LITERATURE CITED}

Archer, J. A., P. F. Arthur, R. M. Herd, P. F. Parnell, and W. S. Pitchford. 1997. Optimum postweaning test for measurement of growth rate, feed intake, and feed efficiency in British breed cattle. J. Anim. Sci. 75:2024-2032.

Arthur, P. F., R. M. Herd, J. Wright, G. Xu, K. Dibley, and E. C. Richardson. 1996. Net feed conversion efficiency and its relationship with other traits in beef cattle. Proc. Aust. Soc. Anim. Prod. 21:107-110.

Arthur, P. F., J. A. Archer, D. J. Johnston, R. M. Herd, E. C. Richardson, and P. F. Parnell. 2001. Genetic and phenotypic variance and covariance components for feed intake, feed efficiency, and other postweaning traits in Angus cattle. J. Anim. Sci. 79:2805-2811.

Cammack, K. M., K. A. Leymaster, T. G. Jenkins, and M. K. Nielsen. 2005. Estimates of genetic parameters for feed intake, feeding behavior, and daily gain in composite ram lambs. J. Anim. Sci. 83:777-785.

Castro Bulle, F. C. P., P. V. Paulino, A. C. Sanches, and R. D. Sainz. 2007. Growth, carcass quality, and protein and energy metabolism in beef cattle with different growth potentials and residual feed intakes. J. Anim. Sci. 85:928-936.

Golden, J. W., M. S. Kerley, and W. H. Kolath. 2008. The relationship of feeding 
behavior to residual feed intake in crossbred Angus steers fed traditional and noroughage diets. J. Anim. Sci. 86:180-186.

Mandal, A., K. P. Pant, D. K. Nandy, P. K. Rout, and R. Roy. 2003. Genetic analysis of growth traits in Muzaffarnagari sheep. Tropical Animal Health and Production. $35: 271-284$.

Nguyen, N. H., C. P. McPhee, and C. M. Wade. 2005. Responses in residual feed intake in lines of Large White pigs selected for growth rate on restricted feeding (measured on ad libitum individual feeding). J. Anim. Breed. Genet. 122:264-270.

Nkrumah, J. D., E. K. Okine, G. W. Mathison, K. Schmid, C. Li, J. A. Basarab, M. A. Price, Z. Wang, and S. S. Moore. 2006. Relationships of feedlot feed efficiency, performance, and feeding behavior with metabolic rate, methane production, and energy partitioning in beef cattle. J. Anim. Sci. 84:145-153.

Rauw, W. M., J. Soler, J. Tibau, J. Reixach, and L. Gomez Raya. 2006a. Feeding time and feeding rate and its relationship with feed intake, feed efficiency, growth rate, and rate of fat deposition in growing Duroc barrows. J. Anim. Sci. 84:3404-3409.

Rauw, W. M., J. Soler, J. Tibau, J. Reixach, and L. Gomez Raya. 2006b. The relationship between residual feed intake and feed intake behavior in group-housed Duroc barrows. J. Anim. Sci. 84:956-962.

Snowder, G. D. and L. D. Van Vleck. 2003. Estimates of genetic parameters and selection strategies to improve the economic efficiency of postweaning growth in lambs. J. Anim. Sci. 81:2704-2713.

Wang. Z, J. D. Nkrumah, C. Li, J. A. Basarab, L. A. Goonewardene, E. K. Okine, D. H. 
Crews Jr., and S. S. Moore. 2006. Test duration for growth, feed intake, and feed efficiency in beef cattle using the GrowSafe System. J. Anim. Sci. 84:2289-2298. 
Chapter 3-Bulls 


\section{ABSTRACT}

Our objective was to determine if a relationship exists between feeding behaviors and performance measurements in beef bulls. During a bull test, 167 beef bulls were group-housed in ten partially covered pens $(14.6$ x $51.2 \mathrm{~m})$. Bulls were ear-tagged with radio frequency transponders for identification purposes and data from GrowSafe (GrowSafe Systems Ltd.) feed nodes were collected and compiled. Data was collected for 101 days from November 2005 to February 2006. Feed was provided ad libitum at three feed nodes per pen. Feed intake, location, number of visits, and duration of visits were investigated. Performance measurements were calculated on the last day of the study: residual feed intake (RFI), average daily gain (ADG), feed:gain ratio, scrotal circumference, ribeye area (REA), fat thickness, intramuscular fat (IMF), and hip height (HH). Statistical analyses were completed using the GLM, FREQ, and TTEST procedures of SAS. Negative RFI bulls had a lower feed intake $(P<0.01)$, lower feed:gain ratio $(P<0.01)$, fewer feeding events $(P<0.01)$ and visits $(P=0.01)$, and less $\operatorname{IMF}(P=0.02)$. Bulls had shorter visits $(P<0.01)$, consumed less per bout $(P<0.01)$, and ate faster $(P<0.01)$ during the daylight hours. During the last 50 days of the study, bulls had longer visits $(P<0.01)$, consumed more per bout $(P<0.01)$, and ate faster $(P<$ 0.01). Eighty-four percent of feeding events occurred between 0600 and 2100 . A difference was seen in visit duration $(P<0.05)$, amount consumed $(P<0.05)$, and eating rate $(P<0.05)$ in all but two pens. In this study, negative RFI bulls ate less with fewer visits to the feeders. As bulls grew, they consumed more feed and ate faster. Behaviors can be observed to identify which animals are likely more efficient while having similar growth characteristics as less efficient bulls. 
Key words: bull, residual feed intake, behavior

\section{INTRODUCTION}

Animals are continually bred to incorporate the best genetic lines into production. Each line is bred for optimal characteristics that will lead to an increase in production. Residual feed intake (RFI) is one such characteristic that is heritable (Archer et al., 1997). Genetics account for approximately $25 \%$ of the observed variability in feed intake and growth rate (Cammack et al., 2005). Animals that are also more efficient will benefit producers because less money is spent on feed, or conversely, more animals may be raised on the same amount of feed. Measuring daily intake has become easier with radio frequency technology. Using new technology, large scale farm operations can determine which animals are more efficient; however, breeding for efficiency may decrease the value of product attained. RFI as a measure of efficiency has little or no correlation with other important production parameters such as muscle yield or fat thickness (Arthur et al., 2001). While tandem selection based on efficiency may not benefit profit potential; however, incorporation of RFI into selection indices has great potential for maximizing profit.

Behavioral differences may also affect efficiency. Animals that are group-housed may exhibit stereotypies not commonly seen in pasture raised and finished animals. Group-housing decreases the amount of space per animal and the amount of available time to feeders which can alter an individual's feeding patterns. Decreasing the amount of available feeding time may cause animals to shift normal patterns of eating to other periods of the day or night. Cattle that eat more frequently may expend more energy from 
traveling to the feeder than animals that eat less often. The objective of this study was to determine how feeding behaviors are related to measures of efficiency and common production traits.

\section{MATERIALS AND METHODS}

All animals in this study were cared for under the guidelines of West Virginia University's Animal Care and Use Committee. During the months of November 2005 through February 2006, 167 bulls were randomly divided among ten pens at the Reymann Memorial Farm, Wardensville, WV. The pens were $14.6 \mathrm{~m}$ x $51.2 \mathrm{~m}$, where $156.2 \mathrm{~m}^{2}$ were covered. The first eight pens (A, B, C, D, E, F, G, H) contained three GrowSafe (GrowSafe Systems Ltd) feed nodes, while the last two (I and J) had four; however, the fourth feed node was not active. Bulls were consigned from several farms throughout West Virginia, which included Angus, Hereford, Charolais, and Red Angus breeds. Radio frequency technology was used to collect behavioral data with Allflex ${ }^{\circledR}$ transponders and GrowSafe ${ }^{\circledR}$ software (Figure 6). Transponders were placed in the left ear of each bull. Each bull was assigned a farm identification number along with the electronic identification number. The following seven items were transmitted to the GrowSafe ${ }^{\circledR}$ software during each visit: animal identification number, location, visit duration, feed displaced, time animal's head lowered, and time and date of visit.

ADG was calculated using the initial and final weights of each animal and the length of the study. RFI was calculated by using regression analysis from the expected and actual intakes of each animal. Feed to gain and gain to feed ratios were calculated. 
Each bull was evaluated for frame, muscle, and structure score by trained evaluators. Scrotal circumference and hip height were measured on the last day of the test. Using ultrasonography, fat thickness (FT), intramuscular fat (IMF), and ribeye area (REA) were measured between the $12^{\text {th }}$ and $13^{\text {th }}$ ribs. Distance transported was calculated for each bull since the animals were consigned from different locations. Prices were recorded for bulls that were sold following the study at the West Virginia Total Performance Bull Sale.

Visits were divided into either feeding events or bouts and non-feeding events. A non-feeding event is when a bull visits the feeder and consumes no food; however, the bull may lower his head. Feed was available at all times. Meal sizes were not calculated during this study, but each feeding bout was divided into five categories: $0 \mathrm{~g}, 0-113.5 \mathrm{~g}$, 113.6-227 g, 228-454 g, and >454 g feed consumed. The days were divided into five periods: $0000-0600,0600-1100,1100-1600,1600-2100$, and 2100-2400. The hours of night and day were defined as 2100-0700 and 0700-2100, respectively.

Nine bulls were removed from data analyses due to incomplete intake data. Several of the bulls analyzed had incomplete observational data and were therefore excluded from statistical analyses on feeding observations. Data was analyzed used TTEST, GLM and FREQ procedures of SAS (SAS Institute Inc). Data was deemed significant with a $P<0.05$.

\section{RESULTS AND DISCUSSION}

Common performance measurements are reported (Table 16). Negative RFI bulls had lower $(P<0.01)$ frame scores, F:G ratios, and feed intakes (FI) (Figure 9). The 
negative RFI bulls gained weight at a similar rate while consuming less feed compared to positive bulls. No difference was seen in ADG. In 2007, Castro Bulle et al. found that more efficient steers had lower FI; however, no difference was seen in G:F or ADG. Nkrumah et al. (2007) reported that high or positive RFI cattle had longer feeding durations and Schwartzkopf-Genswein et al. (2002) found a negative correlation between efficiency and duration time at the feed bunk.

Negative RFI bulls had fewer $(P=0.01)$ visits and feeding events. Golden et al. (2008) found that negative RFI or more efficient steers, ate fewer times per day with no difference in eating rate. A difference was seen between cattle breeds with Charolais eating more often than Angus (Nkrumah, 2007). With a mixed group of bulls in the study, breed may have affected the frequency of visits. The researchers found no difference with duration of daily feeding between breeds. Cattle fed ad libitum have a higher frequency of daily visits then cattle on restricted feeding regimes (SchwartzkopfGenswein et al., 2002). Rauw et al. (2006b) did not find a correlation between RFI and number of visits per day in barrows. Rauw et al. found no difference with frequency of eating and the length of time spent eating in pigs; however, the longer barrows ate, the more feed was consumed. Nkrumah et al. (2006) reported negative RFI steers had fewer feeding events and shorter durations for each event. They also reported that positive RFI steers produce more heat and retain less energy.

Negative RFI bulls had less IMF $(P=0.02)$ and tended to have less BF $(P=$ 0.10). Arthur et al. (2001) found no correlation with rump fat depth and RFI, but a small genetic correlation between RFI and rib fat. Baker et al. (2006) found no relationship between RFI and fat thickness, longissimus muscle area, marbling score, or quality grade. 
Negative RFI animals have a lower intake and retain less fat energy than positive RFI animals (Basarab et al., 2003). Basarab et al. reported that negative RFI animals had a lower liver, stomach, and intestinal weight. If the more efficient animals have lower visceral weights, but no difference in initial or final body weights, the bulls may be depositing more energy in lean tissue.

Schenkel et al. (2004) determined that more efficient animals are leaner because lean muscle is less energy expensive to deposit; however, lean tissue is more energy expensive to maintain. These researchers found a small correlation with fat thickness and RFI. No difference was seen between negative and positive RFI bulls with SC and REA. Low RFI steers deposited more protein and had a higher percent body weight in protein mass (Richardson et al., 2001). McDonagh et al. (2001) found that more efficient steers had less subcutaneous fat with no difference in intramuscular fat, fat color, meat color, or marbling score. Arthur et al. (2001) found no correlation between the SC or REA and RFI in Angus cattle. Negative RFI bulls tended to have a lower hip height $(P=0.10)$. Schenkel et al. (2004) found no relationship between hip height and SC with RFI; however, genetic correlations were found between SC and fat thickness, hip height, ADG, and intake. Correlations with SC were believed to be from the animals with a larger body size having a larger SC and faster growth.

Bulls had shorter visits $(P<0.01)$, consumed less per bout $(P<0.01)$, and ate faster $(P<0.01)$ during the day hours (Table 17). Golden et al. (2008) divided the day into eight three-hour periods and found that the largest intakes occurred during the middle of the day with the least consumed at night. This pattern was seen for both efficient and inefficient steers. Golden et al. also found a numerical difference with eating 
rate in their first experiment, as steers ate faster during the day when most food was consumed. In our study, bulls had the longest durations $(P<0.01)$ with the most feed consumed per bout $(P<0.01)$ before 0600 (Table 18). Bulls had a higher eating rate between 1600-2100 $(P<0.01)$. This may be because animals are less active and less likely to be pushed away from the feeder. Visits were shortest during the early morning and early evening when bulls normally consume the most feed. The decrease in visit time was most likely associated with aggressive behaviors where animals were competing for food. Sixty percent of all visits occurred during the early morning and early evening periods. Schwartzkopf-Genswein et al. (1999) found that steers and heifers consumed food $84 \%$ of the time at the feed bunk. Amount of feed consumed was different for all five periods $(P<0.05)$, along with eating rate $(P<0.01)$.

In our study, bulls had longer visits $(P<0.01)$, consumed more per bout $(P<$ $0.01)$, and ate faster $(P<0.01)$ the last 50 days of the study (Table 19). Rauw et al. (2006a) reported that pigs ate faster and consumed more as they aged. Eating rate was slowest when bulls consumed more than $454 \mathrm{~g}$ of feed per bout $(P<0.01)$, while the eating rate was fastest when bulls consumed between 113.5 and $227 \mathrm{~g}(P<0.01)$. All but two pens $(\mathrm{H}$ and $\mathrm{J} ; \mathrm{I}$ and $\mathrm{J})$ differed from each other with mean duration $(P<0.05)$ and amount of time the head was lowered $(P<0.01)$ (Table 20). All pens differed in the amount bulls consumed except for pens $\mathrm{A}$ and $\mathrm{B}(P<0.05)$, while $\mathrm{C}$ and $\mathrm{G}$ were the only two pens that did not differ in bull eating rate $(P<0.05)$. Positive RFI bulls were closer to the location of sire evaluation $(P=0.01)$. Thus, the stress of travel either had no effect on efficiency or the bulls did not have the same efficiency during the acclimation period 
prior to the study. This difference is expected to be from the genetic basis of each herd, where the more efficient herds were farther from the location of the study.

From this study, negative RFI bulls ate fewer times per day and consumed less feed. Negative RFI bulls were also leaner and were more efficient at gaining weight. As bulls aged over a three month time period, they ate more feed, spent longer eating, and ate at a higher rate. Bulls ate most of their meals between 0600 and 2100. Bulls had different eating rates, duration of feeding and FI per pen. While producers try to control all aspects of production, individual animal behavior will influence efficiency; however, feeding behaviors can be quantified to help identify more efficient animals.

\section{LITERATURE CITED}

Archer, J. A., P. F. Arthur, R. M. Herd, P. F. Parnell, and W. S. Pitchford. 1997. Optimum postweaning test for measurement of growth rate, feed intake, and feed efficiency in British breed cattle. J. Anim. Sci. 75:2024-2032.

Arthur, P. F., J. A. Archer, D. J. Johnston, R. M. Herd, E. C. Richardson, and P. F. Parnell. 2001. Genetic and phenotypic variance and covariance components for feed intake, feed efficiency, and other postweaning traits in Angus cattle. J. Anim. Sci. 79:2805-2811.

Baker, S. D., J. I. Szasz, T. A. Klein, P. S. Kuber, C. W. Hunt, J. B. Glaze Jr., D. Falk, R. Richard, J. C. Miller, R. A. Battaglia, and R. A. Hill. 2006. Residual feed intake of purebred Angus steers: Effects on meat quality and palatability. J. Anim. Sci. 84:938-945.

Basarab, J. A., M. A. Price, J. L. Aalhus, E. K. Okine, W. M. Snelling, and K. L. Lyle. 
2003. Residual feed intake and body composition in young growing cattle. Can. J. Anim. Sci. 83:189-204.

Cammack, K. M., K. A. Leymaster, T. G. Jenkins, and M. K. Nielsen. 2005. Estimates of genetic parameters for feed intake, feeding behavior, and daily gain in composite ram lambs. J. Anim. Sci. 83:777-785.

Castro Bulle, F. C. P., P. V. Paulino, A. C. Sanches, and R. D. Sainz. 2007. Growth, carcass quality, and protein and energy metabolism in beef cattle with different growth potentials and residual feed intakes. J. Anim. Sci. 85:928-936.

Golden, J. W., M. S. Kerley, and W. H. Kolath. 2008. The relationship of feeding behavior to residual feed intake in crossbred Angus steers fed traditional and noroughage diets. J. Anim. Sci. 86:180-186.

McDonagh, M. B., R. M. Herd, E. C. Richardson, V. H. Oddy, J. A. Archer, and P. F. Arthur. 2001. Meat quality and the calpain system of feedlot steers following a single generation of divergent selection for residual feed intake. Australian J. Experimental Agriculture. 41:1013-1021.

Nkrumah, J. D., D. H. Crews Jr., J. A. Basarab. M. A. Price, E. K. Okine, Z. Wang, C. Li, and S. S. Moore. 2007. Genetic and phenotypic relationships of feeding behavior and temperament with performance, feed efficiency, ultrasound, and carcass merit of beef cattle. J. Anim. Sci. 85:2382-2390.

Nkrumah, J. D., E. K. Okine, G. W. Mathison, K. Schmid, C. Li, J. A. Basarab, M. A. Price, Z. Wang, and S. S. Moore. 2006. Relationships of feedlot feed efficiency, performance, and feeding behavior with metabolic rate, methane production, and energy partitioning in beef cattle. J. Anim. Sci. 84:145-153. 
Rauw, W. M., J. Soler, J. Tibau, J. Reixach, and L. Gomez Raya. 2006a. Feeding time and feeding rate and its relationship with feed intake, feed efficiency, growth rate, and rate of fat deposition in growing Duroc barrows. J. Anim. Sci. 84:3404-3409.

Rauw, W. M., J. Soler, J. Tibau, J. Reixach, and L. Gomez Raya. 2006b. The relationship between residual feed intake and feed intake behavior in group-housed Duroc barrows. J. Anim. Sci. 84:956-962.

Richardson, E. C., R. M. Herd, V. H. Oddy, J. M. Thompson, J. A. Archer, and P. F. Arthur. 2001. Body composition and implications for heat production of Angus steer progeny of parents selected for and against residual feed intake. Australian J. Experimental Agriculture. 41:1065-1072.

Schenkel, F. S., S. P. Miller, and J. W. Wilton. 2004. Genetic parameters and breed differences for feed efficiency, growth, and body composition traits of young beef bulls. Can. J. Anim. Sci. 84:177-185.

Schwartzkopf-Genswein, K. S., S. Atwood, and T. A. McAllister. 2002. Relationships between bunk attendance, intake and performance of steers and heifers on varying feeding regimes. Appl. Anim. Behav. Sci. 76:179-188.

Schwartzkopf-Genswein, K. S., C. Huisma, T. A. McAllister. 1999. Validation of a radio frequency identification system for monitoring the feeding patterns of feedlot cattle. Livestock Prod. Sci. 60:27-31. 


\section{CONCLUSION}

Although differences in species occurred, many similarities can help producers to identify characteristics of more efficient animals. Animals that consume less and eat less frequently with meals spaced evenly throughout the day are more likely to be efficient. Each species displays differences in similar feeding behaviors; however, most feed is consumed during the daylight hours. Both beef bulls and rams had higher eating rates during the day, while goats had a higher eating rate at night. This may be from the higher selectivity in feeding of goats that eat at night. All three species had the longest duration for visits at night and had longer durations toward the end of the study. Group-housed animals may displace other animals preventing longer feeding durations so meals should be used for completing more exact feeding behavior conclusion; however, the exact formula for distinguishing meals varies by researcher.

Small noticeable differences appear between efficient and inefficient animals. Behavior is only one part of an animal's overall efficiency. To make a complete equation when selecting for efficiency, the following variables should be included: behavior, feed intake, physical activity, and heat expenditure. When all variables are incorporated into the formula, better management ideas may be generated. With only simple observations of a feeding herd, the animals most likely to be efficient are those with fewer visits to the feeder with evenly spaced meals. 


\section{REFERENCES}

Abijaoudé, J. A., P. Morand-Fehr, J. Tessier, P. Schmidely, and D. Sauvant. 2000. Diet effect on the daily feeding behaviour, frequency and characteristics of meals in dairy goats. Livestock Prod. Sci. 64:29-37.

Allcroft, D. J., B. J. Tolkamp, C. A. Glasbey, and I. Kyriazakis. 2004. The importance of 'memory' in statistical models for animal feeding behaviour. Behavioural Processes 67:99-109.

Archer, J. A. and W. S. Pitchford. 1996. Phenotypic variation in residual feed intake of mice at different ages and its relationship with efficiency of growth, maintenance and body composition. Anim. Sci. 63:149-157.

Archer, J. A., P. F. Arthur, R. M. Herd, P. F. Parnell, and W. S. Pitchford. 1997. Optimum Postweaning Test for Measurement of Growth Rate, Feed Intake, and Feed Efficiency in British Breed Cattle. J. Anim. Sci. 75:2024-2032.

Arthur, P. F., J. A. Archer, D. J. Johnston, R. M. Herd, E. C. Richardson, and P. F. Parnell. 2001. Genetic and phenotypic variance and covariance components for feed intake, feed efficiency, and other postweaning traits in Angus cattle. J. Anim. Sci. 79:2805-2811.

Arthur, P. F., R. M. Herd, J. Wright, G. Xu, K. Dibley, and E. C. Richardson. 1996. Net feed conversion efficiency and its relationship with other traits in beef cattle. Proc. Aust. Soc. Anim. Prod. 21:107-110.

Baker, S. D., J. I. Szasz, T. A. Klein, P. S. Kuber, C. W. Hunt, J. B. Glaze Jr., D. Falk, R. 
Richard, J. C. Miller, R. A. Battaglia, and R. A. Hill. 2006. Residual feed intake of purebred Angus steers: Effects on meat quality and palatability. J. Anim. Sci. 84:938-945.

Basarab, J. A., M. A. Price, J. L. Aalhus, E. K. Okine, W. M. Snelling, and K. L. Lyle. 2003. Residual feed intake and body composition in young growing cattle. Can. J. Anim. Sci. 83:189-204.

Brouns, F. and S. Edwards. 1994. Social rank and feeding behaviour of group-housed sows fed competitively or ad libitum. Appl. Anim. Behav. Sci. 39:225-235.

Cammack, K. M., K. A. Leymaster, T. G. Jenkins, and M. K. Nielsen. 2005. Estimates of genetic parameters for feed intake, feeding behavior, and daily gain in composite ram lambs. J. Anim. Sci. 83:777-785.

Castro Bulle, F. C. P., P. V. Paulino, A. C. Sanches, and R. D. Sainz. 2007. Growth, carcass quality, and protein and energy metabolism in beef cattle with different growth potentials and residual feed intakes. J. Anim. Sci. 85:928-936.

De Haer, L. C. M., P. Luiting, H. L. M. Aarts. 1993. Relations among individual (residual) feed intake, growth performance and feed intake pattern of growing pigs in group housing. Livest. Prod. Sci. 36:233-253.

Felton, E. E. D., J. A. Gulas, and J. E. Warren. 2008. Residual feed intake as a measure of feed efficiency of beef bulls in a test station. (submitted J. Anim. Sci. April 2008).

Georgsson, L. and J. Svendsen. 2002. Degree of competition at feeding differentially affects behavior and performance of group-housed growing-finishing pigs of different relative weights. J. Anim. Sci. 80:376-383.

Golden, J. W., M. S. Kerley, and W. H. Kolath. 2008. The relationship of feeding 
behavior to residual feed intake in crossbred Angus steers fed traditional and noroughage diets. J. Anim. Sci. 86:180-186.

Haddad, S. G. and B. S. Obeidat. 2007. Production efficiency and feeding behavior of Awassi lambs and Baladi kids fed on a high concentrate diet. Small Ruminant Res. 69:23-27.

Hamel, S. and S. D. Côté. 2008. Trade-offs in activity budget in an alpine ungulate: contrasting lactating and nonlactating females. Anim. Behav. 75:217-227.

Kriese, L. A., J. K. Bertrand, and L. L. Benyshek. 1991. Age adjustment factors, heritabilities and genetic correlations for scrotal circumference and related growth traits in Hereford and Brangus bulls. J. Anim. Sci. 69:478-489.

Langhans, W., M. Senn, E. Scharrer, and E. Eggenberger. 1988. Free-feeding pattern of pygmy goats eating a pelleted diet. J. Anim. Physiol. a. Anim. Nutr. 59:160-166.

Luiting, P., J. W. Schrama, W. v. d. Hel, E. M. Urff. 1991. Metabolic differences between White Leghorns selected for high and low residual food consumption. Br. Poult. Sci. 32:763-782.

Mandel, A., K. P. Pant, D. K. Nandy, P. K. Rout, and R. Roy. 2003. Genetic analysis of growth traits in Muzaffarnagari sheep. Tropical Animal Health and Production. $35: 271-284$.

Manninen, M., R. Sormunen-Cristian, L. Jauhiainen, S. Sankari, and T. Soveri. 2006. Effects of feeding frequency on the performance and welfare of mature Hereford cows and their progeny. Livestock Sci. 100:203-215.

McDonagh, M. B., R. M. Herd, E. C. Richardson, V. H. Oddy, J. A. Archer, and P. F. 
Arthur. 2001. Meat quality and the calpain system of feedlot steers following a single generation of divergent selection for residual feed intake. Australian J. Experimental Agriculture. 41:1013-1021.

Morand-Fehr, P., E. Owen, and S. Giger-Reverdin. 1991. Feeding behaviour of goats at the trough. In: Goat Nutrition. EAAP, Wageningen. pp3-12.

Mousel, M. R., W. W. Stroup, and M. K. Nielsen. 2001. Locomotor activity, core body temperature, and circadian rhythms in mice selected for high and low heat loss. J. Anim. Sci. 79:861-868.

Nguyen, N. H., C. P. McPhee, and C. M. Wade. 2005. Responses in residual feed intake in lines of Large White pigs selected for growth rate on restricted feeding (measured on ad libitum individual feeding). J. Anim. Breed. Genet. 122:264-270.

Nielson, M. K., B. A. Freking, L. D. Jones, S. M. Nelson, T. L. Vorderstrasse, and B. A. Hussey. 1997. Divergent selection for heat loss in mice: II. Correlated responses in feed intake, body mass, body composition, and number born through fifteen generations. J. Anim. Sci. 75:1469-1476.

Nkrumah, J. D., D. H. Crews Jr., J. A. Basarab, M. A. Price, E. K. Okine, Z. Wang, C. Li, and S. S. Moore. 2007. Genetic and phenotypic relationships of feeding behavior and temperament with performance, feed efficiency, ultrasound, and carcass merit of beef cattle. J. Anim. Sci. 85:2382-2390.

Nkrumah, J. D., E. K. Okine, G. W. Mathison, K. Schmid, C. Li, J. A. Basarab, M. A. Price, Z. Wang, and S. S. Moore. 2006. Relationships of feedlot feed efficiency, performance, and feeding behavior with metabolic rate, methane production, and energy partitioning in beef cattle. J. Anim. Sci. 84:145-153. 
Olofsson, J. 1999. Competition for total mixed diets fed for ad libitum intake using one or four cows per feeding station. J. Dairy Sci. 82:69-79.

Orr, R. J., P. D. Penning, S. M. Rutter, R. A. Champion, A. Harvey, A. J. Rook. 2001. Intake rate during meals and meal duration for sheep in different hunger states, grazing grass or white clover swards. Appl. Anim. Behav. Sci. 75:33-45.

Pfister, J. A., J. C. Malechek, and D. F. Balph. 1988. Foraging behaviour of goats and sheep in the Caatinga of Brazil. J. Appl. Ecol. 25:379-388.

Ramli, M. N., M. Higashi, Y. Imura, K. Takayama, and Y. Nakanishi. 2005. Growth, feed efficiency, behaviour, carcass characteristics and meat quality of goats fed fermented Bagasse feed. Asian-Aust. J. Anim. Sci. 18:1594-1599.

Rauw, W. M., P. Luiting, M. W. A. Vergstegen, O. Vangen, and P. W. Knap. 2000. Differences in food resource allocation in a long-term selection experiment for litter size in mice. II. Developmental trends in body weight against food intake. Anim. Sci. 71:39-47.

Rauw, W. M., J. Soler, J. Tibau, J. Reixach, and L. Gomez Raya. 2006a. Feeding time and feeding rate and its relationship with feed intake, feed efficiency, growth rate, and rate of fat deposition in growing Duroc barrows. J. Anim. Sci. 84:3404-3409.

Rauw, W. M., J. Soler, J. Tibau, J. Reixach, and L. Gomez Raya. 2006b. The relationship between residual feed intake and feed intake behavior in group-housed Duroc barrows. J. Anim. Sci. 84:956-962.

Richardson, E. C., R. M. Herd, V. H. Oddy, J. M. Thompson, J. A. Archer, and P. F. 
Arthur. 2001. Body composition and implications for heat production of Angus steer progeny of parents selected for and against residual feed intake. Australian J. Experimental Agriculture. 41:1065-1072.

Richardson, E. C., R. M. Herd, J. A. Archer, R. T. Woodgate, and P. F. Arthur. 1998. Steers bred for improved net feed efficiency eat less for the same feedlot performance. Anim. Prod. In Australia. 22:213-216.

Rossi, R., E. Del Prete, J. Rokitzky, and E. Sharrer. 1998. Effects of a high $\mathrm{NaCl}$ diet on eating and drinking patterns in pygmy goats. Physiol. and Behav. 63:601-604.

Schenkel, F. S., S. P. Miller, and J. W. Wilton. 2004. Genetic parameters and breed differences for feed efficiency, growth, and body composition traits of young beef bulls. Can. J. Anim. Sci. 84:177-185.

Schwartzkopf-Genswein, K. S., S. Atwood, and T. A. McAllister. 2002. Relationships between bunk attendance, intake and performance of steers and heifers on varying feeding regimes. Appl. Anim. Behav. Sci. 76:179-188.

Schwartzkopf-Genswein, K. S., C. Huisma, and T. A. McAllister. 1999. Validation of a radio frequency identification system for monitoring the feeding patterns of feedlot cattle. Livestock Prod. Sci. 60:27-31.

Shabi, Z., M. R. Murphy, and U. Moallem. 2005. Within-day feeding behavior of lactating dairy cows measured using a real-time control system. J. Dairy Sci. $88: 1848-1854$.

Shinde, A., D. Verma, and N. Singh. 2004. Social dominance-subordinate relationship in a flock of Marwari goats. Indian J. Anim. Sci. 74:216-219.

Snowder, G. D. and L. D. Van Vleck. 2003. Estimates of genetic parameters and 
selection strategies to improve the economic efficiency of postweaning growth in lambs. J. Anim. Sci. 81:2704-2713.

Solanki, G. S. 1994. Feeding habits and grazing behavior of goats in a semi-arid region of India. Small Ruminant Research. 14:39-43.

Tolkamp, B. J., D. J. Allcroft, E. J. Austin, B. L. Nielsen, and I. Kyriazakis. 1998. Satiety splits feeding behaviour into bouts. J. Theor. Biol. 194:235-250.

Tolkamp, B. J., D. P. N. Schweitzer, and I. Kyriazakis. 2000. The biologically relevant unit for the analysis of short-term feeding behavior of dairy cows. J. Dairy Sci. 83:2057-2068.

Van, D. T. T., I. Ledin, and N. T. Mui. 2002. Feed intake and behaviour of kids and lambs fed sugar cane as the sole roughage with or without concentrate. Anim. Feed Sci. and Tech. 100:79-91.

Wang, Z., J. D. Nkrumah, C. Li, J. A. Basarab, L. A. Goonewardene, E. K. Okine, D. H. Crews Jr., and S. S. Moore. 2006. Test duration for growth, feed intake, and feed efficiency in beef cattle using the GrowSafe System. J. Anim. Sci. 84:2289-2298. 
Table 1. Descriptive statistics for positive and negative RFI bucks ${ }^{1}$

\begin{tabular}{lccc}
\hline & Negative RFI & Positive RFI & P-value \\
\hline Initial BW (kg) & $22.04 \pm 0.96$ & $20.93 \pm 0.49$ & 0.34 \\
Final BW (kg) & $36.67 \pm 0.98$ & $37.09 \pm 1.09$ & 0.77 \\
RFI (kg/d) & $-0.55 \pm 0.11$ & $0.66 \pm 0.15$ & $<0.001$ \\
ADG (kg/d) & $0.32 \pm 0.01$ & $0.32 \pm 0.01$ & 0.98 \\
Average daily intake (g) & $2633.0 \pm 142.53$ & $3423.6 \pm 173.82$ & $<0.001$ \\
\# feeding events & $1390.1 \pm 85.83$ & $1914.4 \pm 125.48$ & 0.002 \\
\# non-feeding events & $278.3 \pm 19.82$ & $425.9 \pm 40.46$ & 0.0025 \\
Eating rate (g/min) & $128.64 \pm 5.92$ & $126.04 \pm 8.98$ & 0.81 \\
\hline${ }^{1}$ Mean \pm SE & & & \\
${ }^{2} \mathrm{n}=12$. & & & \\
${ }^{3}{ }_{\mathrm{n}=10}$ & & &
\end{tabular}


Table 2. Production measurements between negative and positive RFI bucks with adjusted body weight ${ }^{1}$

\begin{tabular}{lccc}
\hline & Negative RFI & Positive RFI $^{\mathbf{3}}$ & $\boldsymbol{P}^{2}$-value \\
\hline Leg circumference $(\mathrm{cm})$ & $39.17 \pm 0.85$ & $38.2 \pm 0.68$ & 0.40 \\
Adjusted leg circumference $(\mathrm{cm})$ & $39.51 \pm 0.97$ & $38.19 \pm 0.73$ & 0.31 \\
Fat thickness $(\mathrm{cm})$ & $0.16 \pm 0.01$ & $0.17 \pm 0.02$ & 0.51 \\
Adjusted fat thickness $(\mathrm{cm})$ & $0.16 \pm 0.01$ & $0.17 \pm 0.02$ & 0.50 \\
REA $\left(\mathrm{cm}^{2}\right)$ & $10.86 \pm 0.20$ & $10.39 \pm 0.44$ & 0.35 \\
Adjusted REA $\left(\mathrm{cm}^{2}\right)$ & $10.95 \pm 0.19$ & $10.38 \pm 0.33$ & 0.14 \\
\hline
\end{tabular}

${ }^{1}$ Measurements with body weight adjusted to $36.56 \mathrm{~kg}$

${ }^{2} \mathrm{n}=12$

${ }^{3} \mathrm{n}=10$ 
Table 3. Production measurements on birth number with adjusted body weight in bucks ${ }^{1}$

\begin{tabular}{lccc}
\hline & Single $^{2}$ & Twin/Triplet $^{3}$ & $\boldsymbol{P}^{2}$-value \\
\hline Leg circumference $(\mathrm{cm})$ & $40.00 \pm 0.82$ & $38.44 \pm 0.64$ & 0.29 \\
Adjusted leg circumference $(\mathrm{cm})$ & $38.02 \pm 0.98$ & $39.03 \pm 0.73$ & 0.52 \\
Fat thickness $(\mathrm{cm})$ & $0.21 \pm 0.05$ & $0.16 \pm 0.01$ & 0.36 \\
Adjusted fat thickness $(\mathrm{cm})$ & $0.20 \pm 0.04$ & $0.16 \pm 0.01$ & 0.45 \\
REA $\left(\mathrm{cm}^{2}\right)$ & $11.50 \pm 0.64$ & $10.46 \pm 0.22$ & 0.08 \\
Adjusted REA $\left(\mathrm{cm}^{2}\right)$ & $10.83 \pm 0.47$ & $10.66 \pm 0.21$ & 0.12 \\
\hline
\end{tabular}

${ }^{1}$ Measurements with body weight adjusted to $36.56 \mathrm{~kg}$

${ }^{2} n=4$

${ }^{3} \mathrm{n}=18$ 
Table 4. Percentage of meals during each time period

\begin{tabular}{lccccc}
\hline & $\mathrm{x}=0$ & $0<\mathrm{x} \leq 113.5$ & $113.5<\mathrm{x} \leq 227$ & $227<\mathrm{x} \leq 454$ & $\mathrm{x}>454$ \\
\hline $0000-0600$ & 1.58 & 5.71 & 1.15 & 0.35 & 0.12 \\
$0600-1100$ & 5.82 & 18.24 & 2.59 & 0.75 & 0.15 \\
$1100-1600$ & 5.84 & 17.79 & 2.27 & 0.54 & 0.10 \\
$1600-2100$ & 7.10 & 22.58 & 2.53 & 0.56 & 0.07 \\
$2100-2400$ & 0.88 & 2.63 & 0.43 & 0.18 & 0.03 \\
\hline
\end{tabular}


Table 5. Descriptive statistics for goat means per visit

\begin{tabular}{lcc}
\hline & Day $^{1}$ & Night $^{2}$ \\
\hline Duration (s) & $74 \pm 1^{\mathrm{a}}$ & $72 \pm 2^{\mathrm{a}}$ \\
Head lowered (s) & $33 \pm 1^{\mathrm{a}}$ & $32 \pm 1^{\mathrm{b}}$ \\
Consumed (g) & $49 \pm 1^{\mathrm{a}}$ & $56 \pm 1^{\mathrm{b}}$ \\
Eating rate (g/min) & $91 \pm 2^{\mathrm{a}}$ & \\
\hline${ }^{1} 0700-1900$ & & \\
${ }^{2} 0000-0700$ and 1900-2400 & \\
${ }^{\mathrm{a}-\mathrm{b}}$ Difference in superscript denotes $P<0.01$ &
\end{tabular}


Table 6. Feeding behavior means per time period in bucks

\begin{tabular}{lrrrrr}
\hline & $0000-0600$ & $0600-1100$ & $1100-1600$ & $1600-2100$ & $2100-2400$ \\
\hline Duration (s) & $120 \pm 4^{\mathrm{a}}$ & $75 \pm 2^{\mathrm{c}}$ & $97 \pm 2^{\mathrm{b}}$ & $74 \pm 2^{\mathrm{c}}$ & $112 \pm 5^{\mathrm{a}}$ \\
Head down(s) & $48 \pm 1^{\mathrm{a}}$ & $34 \pm 1^{\mathrm{c}}$ & $43 \pm 1^{\mathrm{b}}$ & $33 \pm 1^{\mathrm{c}}$ & $50 \pm 2^{\mathrm{a}}$ \\
Consumed (g) & $85 \pm 2^{\mathrm{a}}$ & $68 \pm 1^{\mathrm{c}}$ & $63 \pm 1^{\mathrm{d}}$ & $58 \pm 1^{\mathrm{e}}$ & $77 \pm 3^{\mathrm{b}}$ \\
$\begin{array}{l}\text { Eating rate } \\
\text { (g/min) }\end{array}$ & $154 \pm 6^{\mathrm{a}}$ & $149 \pm 3^{\mathrm{a}}$ & $103 \pm 3^{\mathrm{c}}$ & $117.0 \pm 2.9^{\mathrm{b}}$ & $120 \pm 8^{\mathrm{bc}}$ \\
\hline
\end{tabular}

${ }^{\mathrm{a}-\mathrm{e}}$ Difference in row superscript is significant at $P<0.05$ 
Table 7. Percentage of observations at each scale for each time period

\begin{tabular}{lcc}
\hline & Scale A & Scale B \\
\hline $0000-0600$ & 37.17 & 62.83 \\
$0600-1100$ & 39.73 & 60.27 \\
$1100-1600$ & 43.91 & 56.09 \\
$1600-2100$ & 42.38 & 57.62 \\
$2100-2400$ & 42.26 & 57.74 \\
Average & 41.59 & 58.41 \\
\hline
\end{tabular}


Table 8. Ram ration

\begin{tabular}{ll}
\hline Nutrient & $\%$ \\
\hline Crude Protein & 16.00 \\
Crude Fat & 2.91 \\
Crude Fiber & 22.50 \\
TDN & 65.25 \\
Calcium & 0.85 \\
Total Phosphorus & 0.39 \\
Sodium & 0.50 \\
\hline
\end{tabular}


Table 9. Descriptive statistics for RFI in rams

\begin{tabular}{|c|c|c|c|c|c|c|}
\hline & Year 1 & & & Year 2 & & \\
\hline & Negative $^{1}$ & Positive $^{2}$ & P-value & Negative $^{3}$ & Positive $^{4}$ & P-value \\
\hline Initial BW (kg) & $35.48 \pm 2.09$ & $35.96 \pm 2.15$ & 0.87 & $37.84 \pm 2.02$ & $35.76 \pm 1.88$ & 0.45 \\
\hline Final BW (kg) & $53.59 \pm 1.89$ & $52.58 \pm 2.40$ & 0.75 & $65.45 \pm 2.14$ & $64.51 \pm 1.98$ & 0.75 \\
\hline RFI (kg/d) & $-0.25 \pm 0.06$ & $0.24 \pm 0.05$ & $<0.001$ & $-0.20 \pm 0.032$ & $0.18 \pm 0.040$ & $<0.001$ \\
\hline $\operatorname{ADG}(\mathrm{kg} / \mathrm{d})$ & $0.33 \pm 0.02$ & $0.31 \pm 0.02$ & 0.37 & $0.44 \pm 0.015$ & $0.46 \pm 0.012$ & 0.32 \\
\hline $\begin{array}{l}\text { Avg intake } \\
(\mathrm{kg} / \mathrm{d})\end{array}$ & $1.73 \pm 0.08$ & $2.16 \pm 0.09$ & 0.002 & $2.63 \pm 0.073$ & $3.03 \pm 0.089$ & 0.001 \\
\hline Age (d) & $134.72 \pm 9.62$ & $133.89 \pm 8.97$ & 0.95 & $92.75 \pm 3.33$ & $85.96 \pm 2.99$ & 0.14 \\
\hline
\end{tabular}


Table 10. Descriptive statistics for birth number in rams

\begin{tabular}{|c|c|c|c|c|c|c|}
\hline & Year 1 & & & Year 2 & & \\
\hline $\operatorname{ADG}(\mathrm{kg} / \mathrm{d})$ & $0.30 \pm 0.02$ & $0.34 \pm 0.017$ & 0.08 & $0.44 \pm 0.031$ & $0.45 \pm 0.010$ & 0.63 \\
\hline RFI (kg/d) & $-0.029 \pm 0.11$ & $0.025 \pm 0.05$ & 0.64 & $-0.12 \pm 0.11$ & $0.034 \pm 0.040$ & 0.13 \\
\hline $\begin{array}{l}\text { Initial wt } \\
(\mathrm{kg})\end{array}$ & $42.11 \pm 1.65$ & $30.30 \pm 1.5$ & $<0.001$ & $46.83 \pm 1.64$ & $34.45 \pm 1.38$ & $<0.001$ \\
\hline Final wt (kg) & $57.97 \pm 2.09$ & $48.91 \pm 1.72$ & 0.002 & $75.41 \pm 1.60$ & $62.56 \pm 1.46$ & $<0.001$ \\
\hline $\begin{array}{l}\text { Avg intake } \\
(\mathrm{kg} / \mathrm{d})\end{array}$ & $1.97 \pm 0.13$ & $1.93 \pm 0.076$ & 0.80 & $2.96 \pm 0.089$ & $2.83 \pm 0.078$ & 0.46 \\
\hline $\begin{array}{l}\text { No. Feeding } \\
\text { bouts }\end{array}$ & $1082.8 \pm 85.16$ & $1047.4 \pm 45.72$ & 0.72 & $1455.4 \pm 91.45$ & $1419.8 \pm 51.73$ & 0.76 \\
\hline $\begin{array}{l}\text { Fat thickness } \\
(\mathrm{cm})\end{array}$ & $0.36 \pm 0.02$ & $0.28 \pm 0.01$ & $<0.001$ & $0.20 \pm 0.02$ & $0.17 \pm 0.01$ & 0.25 \\
\hline
\end{tabular}

\footnotetext{
${ }^{1} \mathrm{n}=17$

${ }^{2} \mathrm{n}=20$

${ }^{3} \mathrm{n}=8$

${ }^{4} \mathrm{n}=36$
} 
Table 11. Breed comparisons in the $2^{\text {nd }}$ year

\begin{tabular}{lccc}
\hline & Dorset $^{1}$ & Suffolk $^{2}$ & P-value \\
\hline Age $(\mathrm{d})$ & $97.58 \pm 3.29$ & $83.67 \pm 2.59$ & 0.002 \\
ADG $(\mathrm{kg} / \mathrm{d})$ & $0.43 \pm 0.01$ & $0.47 \pm 0.01$ & 0.05 \\
RFI (kg/d) & $-0.049 \pm 0.06$ & $0.042 \pm 0.05$ & 0.25 \\
Initial wt (kg) & $34.25 \pm 2.15$ & $38.25 \pm 1.73$ & 0.16 \\
Final wt (kg) & $61.16 \pm 2.18$ & $67.43 \pm 1.78$ & 0.03 \\
Mean intake (kg/d) & $2.62 \pm 0.09$ & $2.99 \pm 0.08$ & 0.004 \\
No. feeding bouts & $1329.5 \pm 85.10$ & $1487.1 \pm 48.03$ & 0.09 \\
Eating rate (g/min) & $96.20 \pm 6.84$ & $87.26 \pm 3.41$ & 0.25 \\
Scrotal Circ (cm) & $26.84 \pm 0.91$ & $27.5 \pm 0.47$ & 0.52 \\
Fat thickness (cm) & $0.41 \pm 0.04$ & $0.46 \pm 0.03$ & 0.28 \\
LEA (cm $\left.{ }^{2}\right)$ & $16.40 \pm 0.63$ & $19.36 \pm 0.63$ & 0.003 \\
\hline${ }^{1} \mathrm{n}=17$ & & & \\
${ }^{2} \mathrm{n}=27$ & & &
\end{tabular}


Table 12. Descriptive statistics for ram means per visit

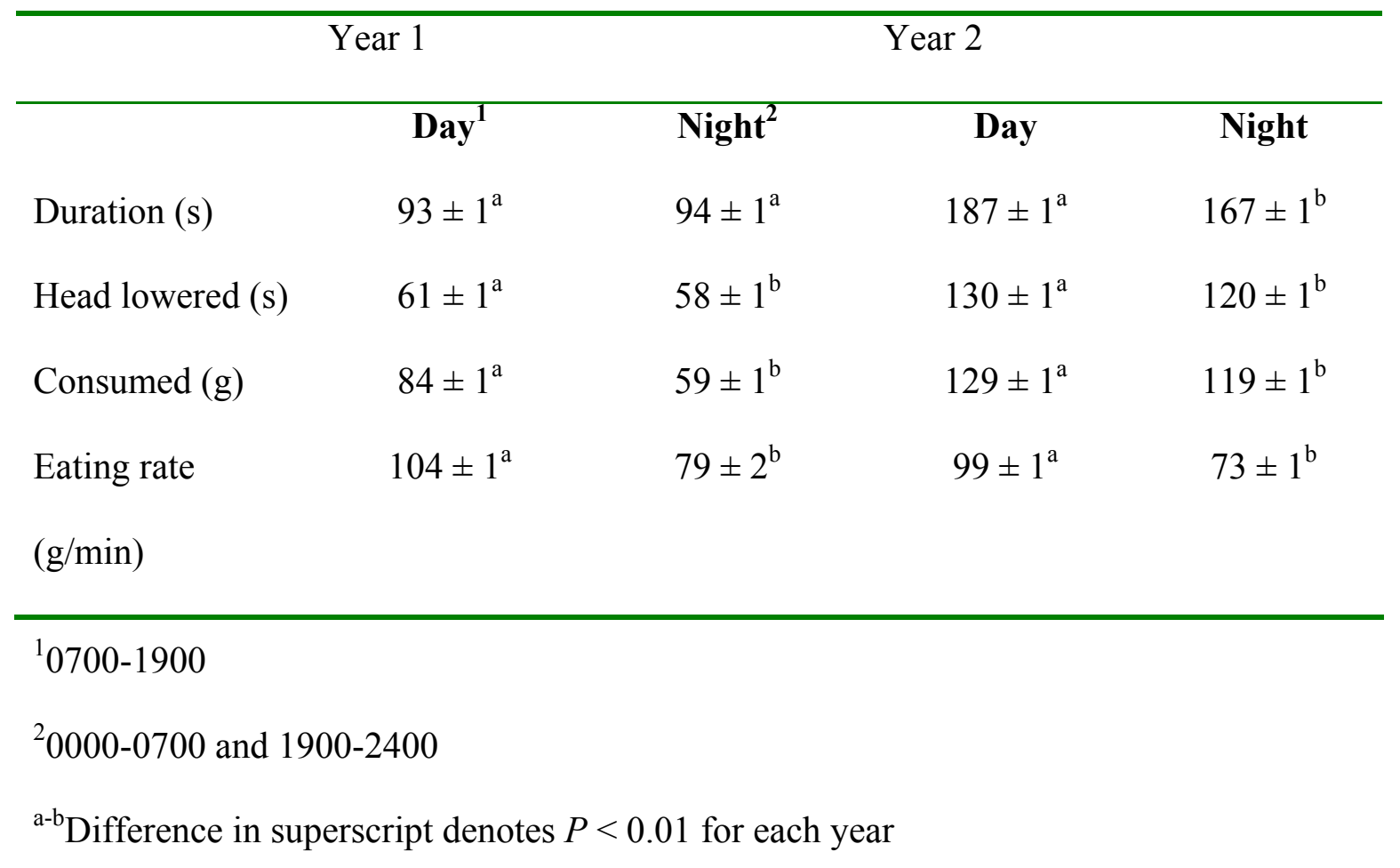


Table 13. Feeding behavior means per time period in year 1 rams

\begin{tabular}{lccccc}
\hline & $0000-0600$ & $0600-1100$ & $1100-1600$ & $1600-2100$ & $2100-2400$ \\
\hline Duration (s) & $110 \pm 2^{\mathrm{a}}$ & $90 \pm 1^{\mathrm{d}}$ & $103 \pm 1^{\mathrm{b}}$ & $80 \pm 1^{\mathrm{e}}$ & $97 \pm 2^{\mathrm{c}}$ \\
Head down(s) & $63 \pm 1^{\mathrm{b}}$ & $60 \pm 1^{\mathrm{c}}$ & $66 \pm 1^{\mathrm{a}}$ & $53 \pm 1^{\mathrm{d}}$ & $61 \pm 1^{\mathrm{bc}}$ \\
Consumed (g) & $57 \pm 1^{\mathrm{d}}$ & $83 \pm 1^{\mathrm{b}}$ & $86 \pm 1^{\mathrm{a}}$ & $71 \pm 1^{\mathrm{c}}$ & $58 \pm 2^{\mathrm{d}}$ \\
Eating rate & $73 \pm 3^{\mathrm{b}}$ & $101 \pm 2^{\mathrm{a}}$ & $100 \pm 2^{\mathrm{a}}$ & $103 \pm 2^{\mathrm{a}}$ & $72 \pm 3^{\mathrm{b}}$ \\
$(\mathrm{g} / \mathrm{s})$ & & & & & \\
\hline
\end{tabular}

${ }^{\text {a-e }}$ Differences in row significantly different at $P<0.05$ 
Table 14. Feeding behavior means per time period in year 2 rams

\begin{tabular}{lrrrrr}
\hline & $0000-0600$ & $0600-1100$ & $1100-1600$ & $1600-2100$ & $2100-2400$ \\
\hline Duration (s) & $182 \pm 2^{\mathrm{b}}$ & $169 \pm 1^{\mathrm{c}}$ & $203 \pm 2^{\mathrm{a}}$ & $179 \pm 1^{\mathrm{b}}$ & $1489 \pm 2^{\mathrm{d}}$ \\
Head down(s) & $130 \pm 1^{\mathrm{b}}$ & $122 \pm 1^{\mathrm{d}}$ & $138 \pm 1^{\mathrm{a}}$ & $125 \pm 1^{\mathrm{c}}$ & $105 \pm 1^{\mathrm{e}}$ \\
Consumed (g) & $113 \pm 1^{\mathrm{c}}$ & $116 \pm 1^{\mathrm{b}}$ & $137 \pm 1^{\mathrm{a}}$ & $134 \pm 1^{\mathrm{a}}$ & $116 \pm 1^{\mathrm{bc}}$ \\
$\begin{array}{l}\text { Eating rate } \\
\text { (g/min) }\end{array}$ & $62 \pm 2^{\mathrm{d}}$ & $91 \pm 2^{\mathrm{b}}$ & $108 \pm 2^{\mathrm{a}}$ & $89 \pm 2^{\mathrm{b}}$ & $74 \pm 3^{\mathrm{c}}$ \\
\hline
\end{tabular}

${ }^{\text {a-e }}$ Differences in row significantly different at $P<0.05$ 
Table 15. Descriptive statistics for RFI in bulls

\begin{tabular}{|c|c|c|c|}
\hline & Negative $^{1}$ & Positive $^{2}$ & $P$-value \\
\hline Age (d) & $244.94 \pm 2.41$ & $241.88 \pm 2.86$ & 0.42 \\
\hline $\mathrm{ADG}(\mathrm{kg} / \mathrm{d})$ & $1.89 \pm 0.03$ & $1.93 \pm 0.03$ & 0.28 \\
\hline $\operatorname{RFI}(\mathrm{kg} / \mathrm{d})$ & $-0.64 \pm 0.06$ & $0.65 \pm 0.05$ & $<0.001$ \\
\hline Feed:gain (kg/kg) & $6.78 \pm 0.09$ & $7.45 \pm 0.11$ & $<0.001$ \\
\hline Total Intake (kg) & $1243.2 \pm 16.7$ & $1391.7 \pm 16.5$ & $<0.001$ \\
\hline No. visits & $3222.6 \pm 85.6$ & $3522.8 \pm 83.9$ & 0.01 \\
\hline Feeding events & $3005.9 \pm 77.2$ & $3293.0 \pm 77.1$ & $<0.01$ \\
\hline Non-feeding events & $216.66 \pm 11.86$ & $226.01 \pm 10.81$ & 0.56 \\
\hline REA & $90.81 \pm 0.99$ & $91.58 \pm 0.96$ & 0.58 \\
\hline Back fat & $1.05 \pm 0.03$ & $1.13 \pm 0.04$ & 0.10 \\
\hline IMF & $3.90 \pm 0.08$ & $4.20 \pm 0.10$ & 0.02 \\
\hline Hip height & $50.23 \pm 0.15$ & $50.58 \pm 0.15$ & 0.10 \\
\hline Distance $(\mathrm{km})$ & $249.61 \pm 11.96$ & $207.98 \pm 10.69$ & 0.01 \\
\hline Frame score & $5.62 \pm 0.7$ & $5.86 \pm 0.7$ & 0.01 \\
\hline \multicolumn{4}{|l|}{${ }^{1} \mathrm{n}=77$} \\
\hline${ }^{2} \mathrm{n}=81$ & & & \\
\hline
\end{tabular}


Table 16. Descriptive statistics for bull means per visit

\begin{tabular}{lccc}
\hline & Day $^{1}$ & Night $^{2}$ & P-value \\
\hline Duration of visit (s) & $175 \pm 1$ & $366 \pm 1$ & $<0.001$ \\
Time Head lowered (s) & $109 \pm 1$ & $205 \pm 1$ & $<0.001$ \\
Amount Consumed (g) & $340 \pm 1$ & $485 \pm 1$ & $<0.001$ \\
Eating rate (g/min) & $209 \pm 1$ & $117 \pm 1$ & \\
\hline${ }^{1} 0700-1900$ & & & \\
${ }^{2}$ 0000-0700 and 1900-2400 & & & \\
${ }^{\mathrm{a}-\mathrm{b}}$ Difference in superscript denotes $P<0.01$ & &
\end{tabular}


Table 17. Feeding behavior means per time period in bulls

\begin{tabular}{lrrrrr}
\hline & $0000-0600$ & $0600-1100$ & $1100-1600$ & $1600-2100$ & $2100-2400$ \\
\hline Duration (s) & $420 \pm 2^{\mathrm{a}}$ & $159 \pm 1^{\mathrm{e}}$ & $210 \pm 1^{\mathrm{c}}$ & $199 \pm 1^{\mathrm{d}}$ & $339 \pm 2^{\mathrm{b}}$ \\
Head down(s) & $222 \pm 1^{\mathrm{a}}$ & $100 \pm 1^{\mathrm{e}}$ & $125 \pm 1^{\mathrm{c}}$ & $123 \pm 1^{\mathrm{d}}$ & $199 \pm 1^{\mathrm{b}}$ \\
$\begin{array}{l}\text { Consumed }(\mathrm{g}) \\
\text { Eating rate }\end{array}$ & $508 \pm 2^{\mathrm{a}}$ & $289 \pm 1^{\mathrm{e}}$ & $386 \pm 1^{\mathrm{d}}$ & $396 \pm 1^{\mathrm{c}}$ & $483 \pm 2^{\mathrm{b}}$ \\
(g/min) & $108 \pm 1^{\mathrm{e}}$ & $199 \pm 1^{\mathrm{c}}$ & $205 \pm 1^{\mathrm{b}}$ & $208 \pm 1^{\mathrm{a}}$ & $121 \pm 2^{\mathrm{d}}$ \\
\hline
\end{tabular}

${ }^{\text {a-e }}$ Differences in row significantly different at $P<0.05$ 
Table 18. Mean values for bulls during first and last 50 days of study

\begin{tabular}{lccc}
\hline & Beginning & End & $P$-value \\
\hline Duration of visit (s) & $201 \pm 1$ & $233 \pm 1$ & $<0.001$ \\
Time Head lowered (s) & $122 \pm 1$ & $137 \pm 1$ & $<0.001$ \\
Amount Consumed (g) & $328 \pm 1$ & $425 \pm 1$ & $<0.001$ \\
Eating rate (g/min) & $181 \pm 1$ & $202 \pm 1$ & $<0.001$ \\
\hline
\end{tabular}


Table 19. Mean differences by pen for bulls

\begin{tabular}{lcccc}
\hline & Duration of & Time Head & Amount & Eating rate \\
& visit (s) & Lowered (s) & consumed (g) & (g/min) \\
\hline A & $179 \pm 1^{\mathrm{i}}$ & $108 \pm 1^{\mathrm{g}}$ & $332 \pm 2^{\mathrm{h}}$ & $193 \pm 1^{\mathrm{d}}$ \\
B & $198 \pm 1^{\mathrm{g}}$ & $134 \pm 1^{\mathrm{d}}$ & $335 \pm 2^{\mathrm{h}}$ & $175 \pm 1^{\mathrm{g}}$ \\
C & $244 \pm 2^{\mathrm{c}}$ & $152 \pm 1^{\mathrm{a}}$ & $486 \pm 2^{\mathrm{a}}$ & $198 \pm 1^{\mathrm{c}}$ \\
$\mathrm{D}$ & $203 \pm 1^{\mathrm{f}}$ & $142 \pm 1^{\mathrm{c}}$ & $361 \pm 2^{\mathrm{f}}$ & $184 \pm 1^{\mathrm{f}}$ \\
E & $253 \pm 2^{\mathrm{b}}$ & $146 \pm 1^{\mathrm{b}}$ & $393 \pm 2^{\mathrm{d}}$ & $165 \pm 1^{\mathrm{h}}$ \\
F & $280 \pm 2^{\mathrm{a}}$ & $154 \pm 1^{\mathrm{a}}$ & $404 \pm 2^{\mathrm{c}}$ & $159 \pm 1^{\mathrm{i}}$ \\
$\mathrm{G}$ & $186 \pm 1^{\mathrm{h}}$ & $118 \pm 1^{\mathrm{f}}$ & $310 \pm 2^{\mathrm{i}}$ & $200 \pm 1^{\mathrm{c}}$ \\
$\mathrm{H}$ & $220 \pm 2^{\mathrm{d}}$ & $101 \pm 1^{\mathrm{h}}$ & $412 \pm 2^{\mathrm{b}}$ & $218 \pm 1^{\mathrm{a}}$ \\
I & $216 \pm 2^{\mathrm{de}}$ & $127 \pm 1^{\mathrm{e}}$ & $347 \pm 2^{\mathrm{g}}$ & $211 \pm 1^{\mathrm{b}}$ \\
J & $214 \pm 2^{\mathrm{e}}$ & $117 \pm 1^{\mathrm{f}}$ & $367 \pm 2^{\mathrm{e}}$ & $188 \pm 1^{\mathrm{e}}$ \\
\hline
\end{tabular}

${ }^{\text {a-i }}$ Means within column with different superscript different at $P<0.05$ 


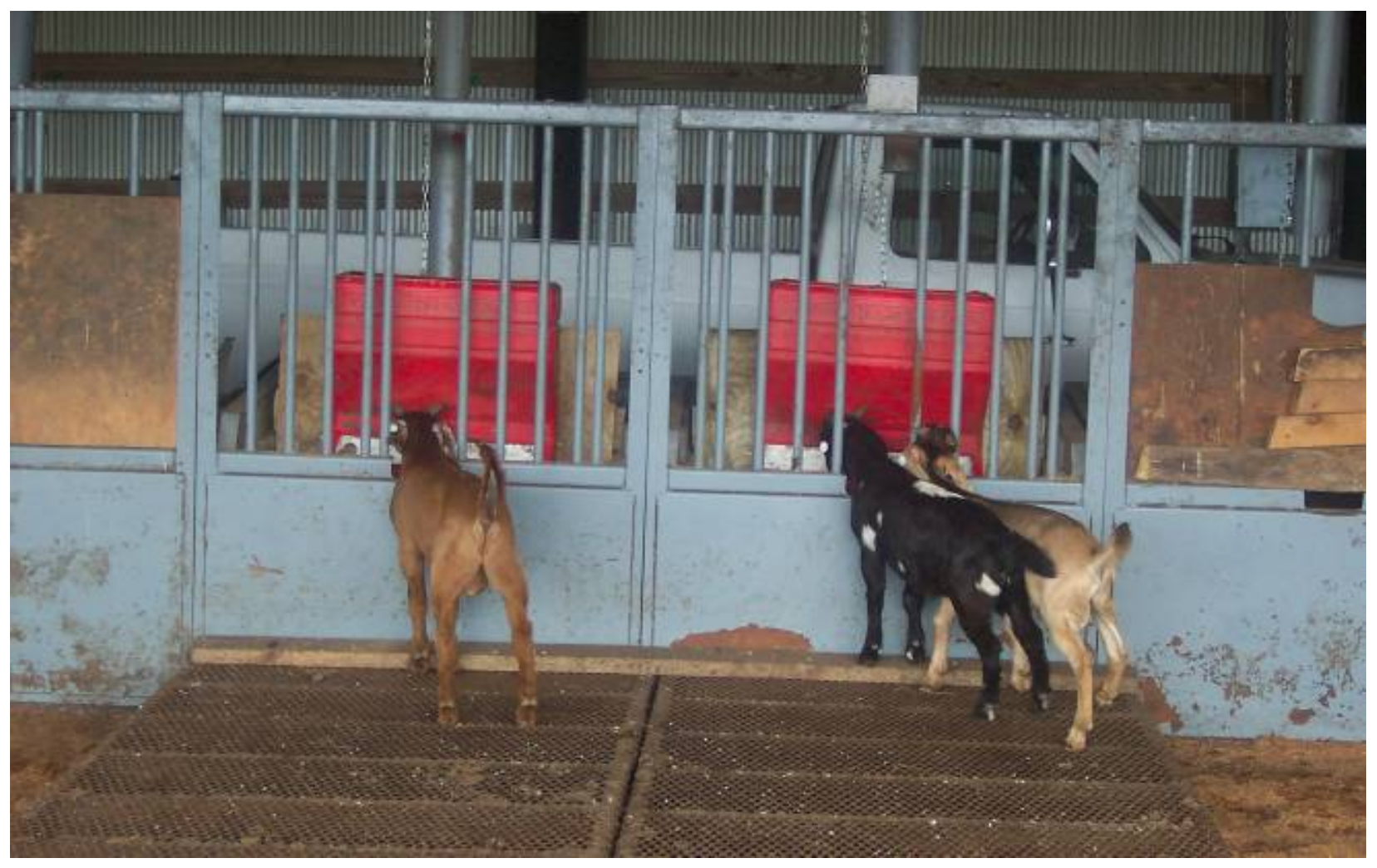

Figure 1. Modifications to prevent multiple animals from eating at once. The Kane ${ }^{\circledR}$ nursery feeder is placed in the GrowSafe ${ }^{\circledR}$ feed node to allow goats to reach the feed. 


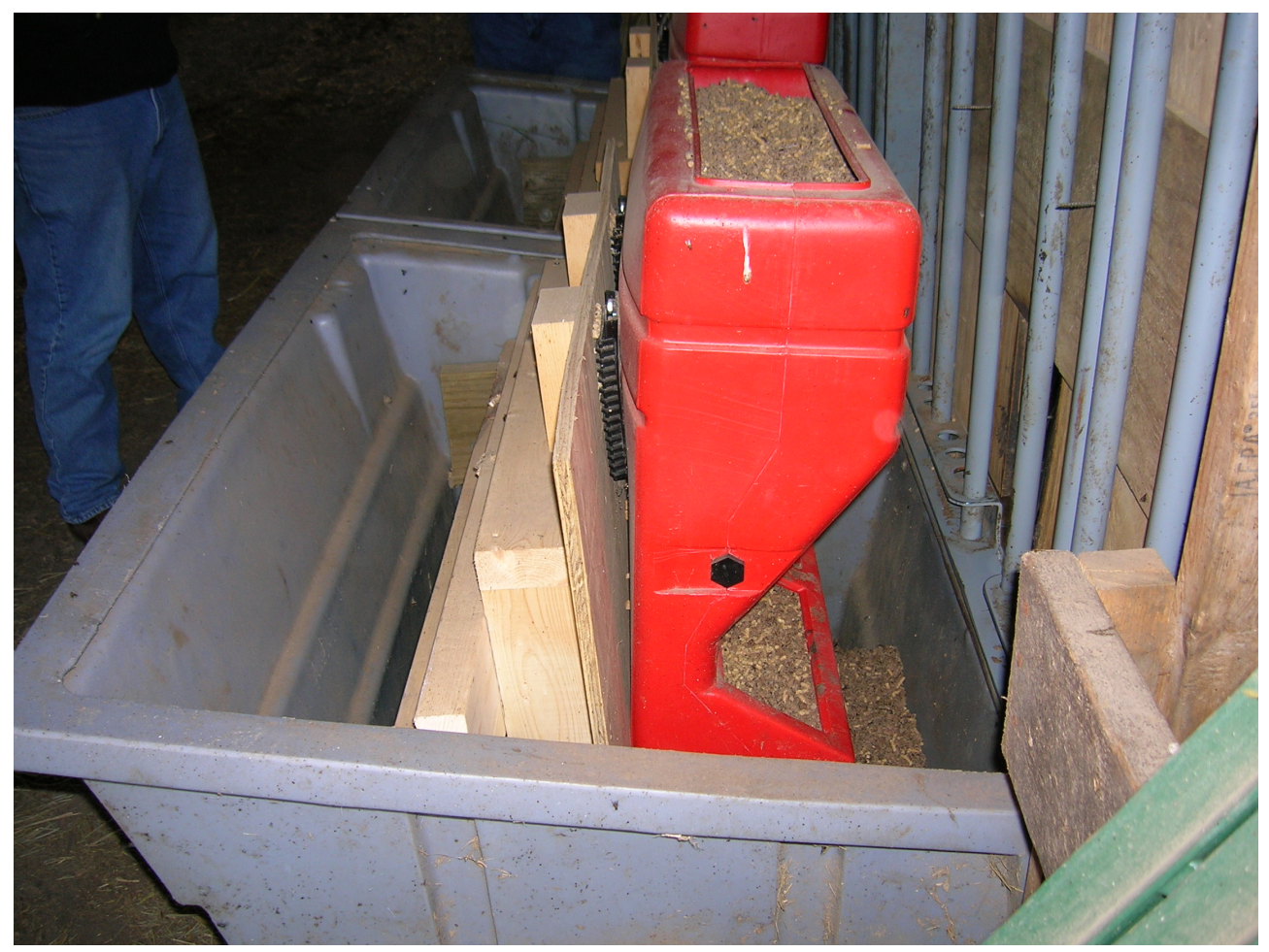

Figure 2. Modifications to GrowSafe ${ }^{\circledR}$ feed node with Kane ${ }^{\circledR}$ nursery feeder. The Kane nursery feeder was placed within the feed node to monitor feed disappearance. The feed node was modified for goats and sheep since the animals could not reach to the bottom of the node. The plywood front prevented multiple animals from feeding at one time. 


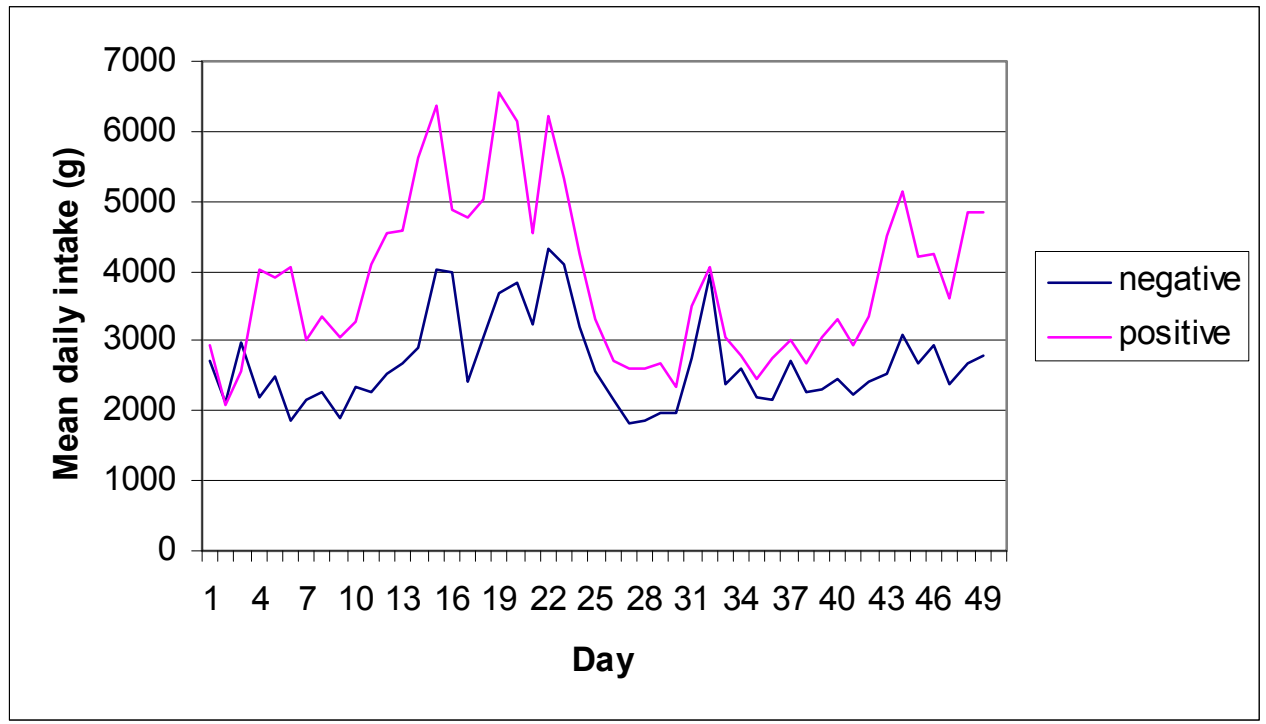

Figure 3. Mean daily intake for negative and positive RFI bucks. 


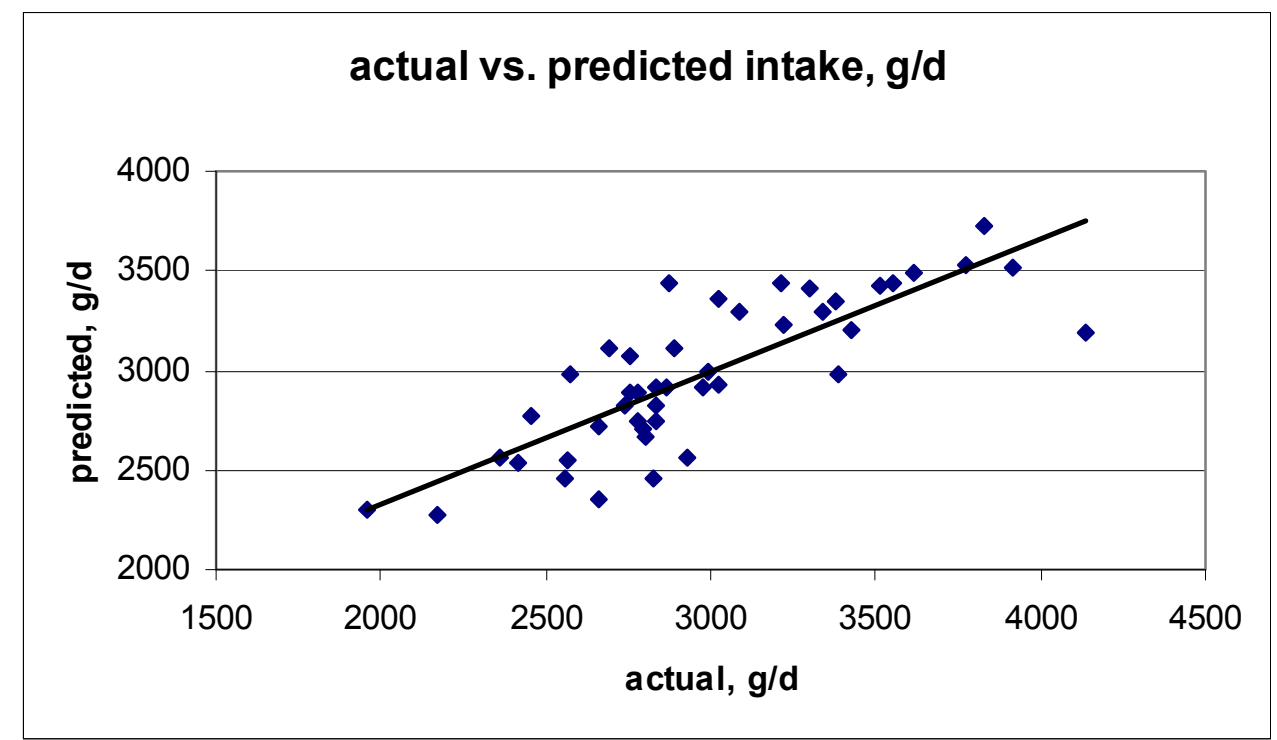

Figure 4. RFI plot for year 2 ram intake data. 


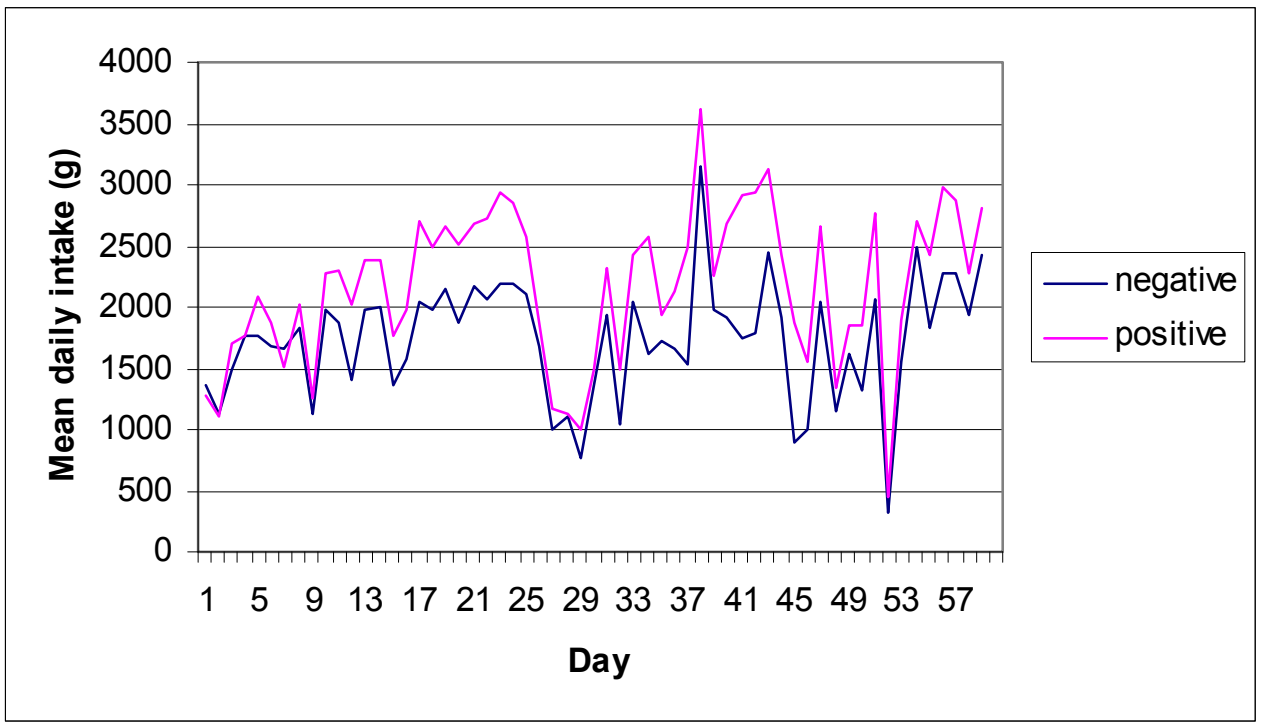

Figure 5. Mean daily intake for Year 1 positive and negative RFI rams. 


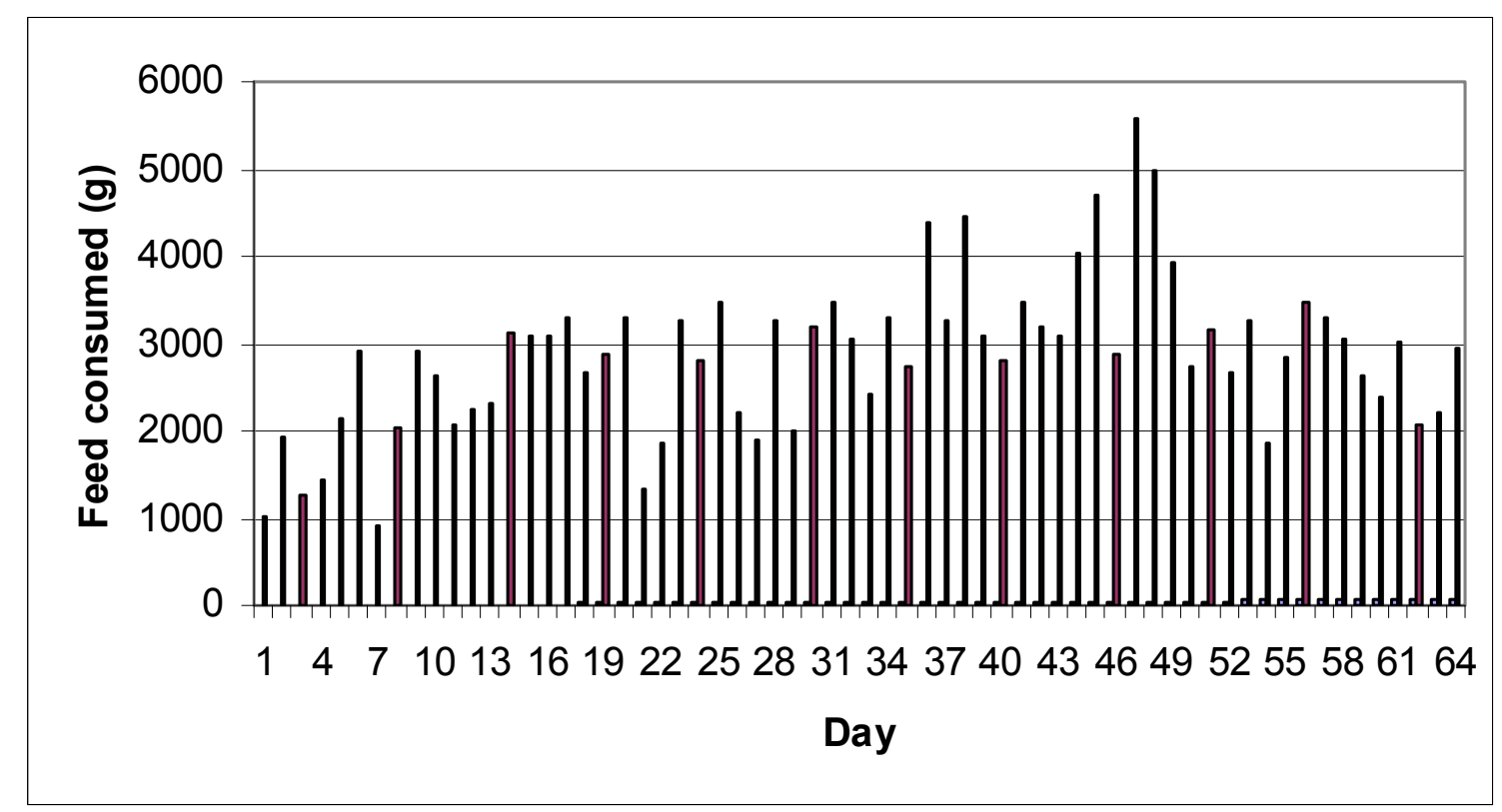

Figure 6. Daily intake for one ram. 


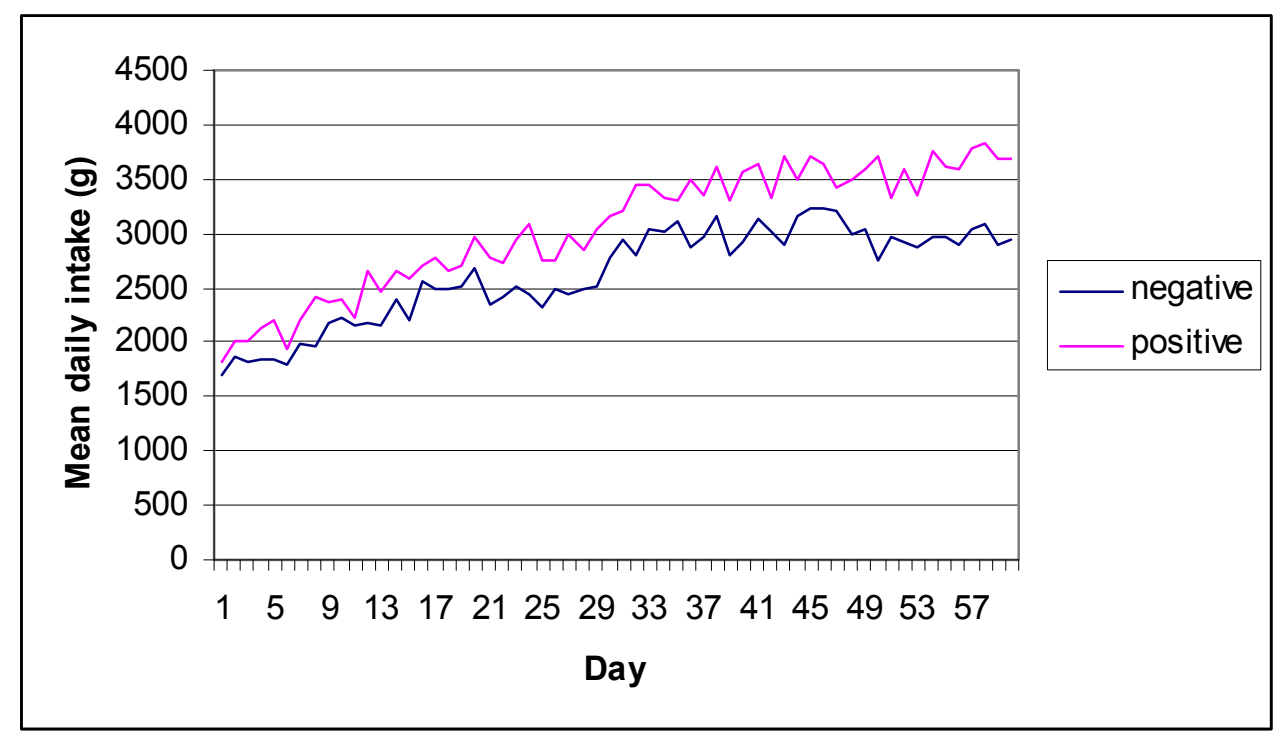

Figure 7. Mean daily intake for Year 2 positive and negative RFI rams. 


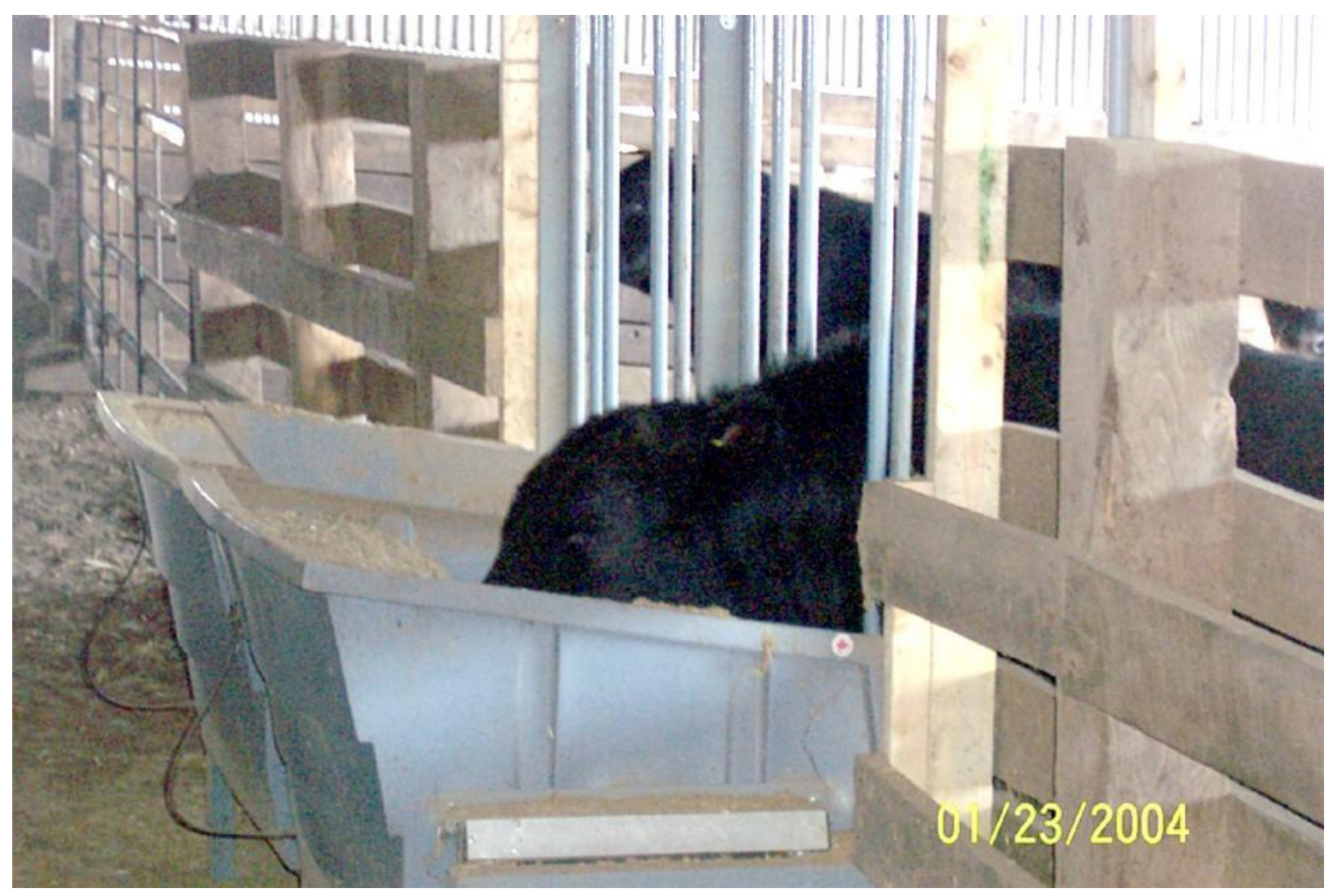

Figure 8. GrowSafe feeding system. A bull is eating from one of two GrowSafe feed nodes pictured. Feed nodes transmit data to the GrowSafe feeding system for data collection. This feeding system is designed so only one animal can feed at each node at one time. 


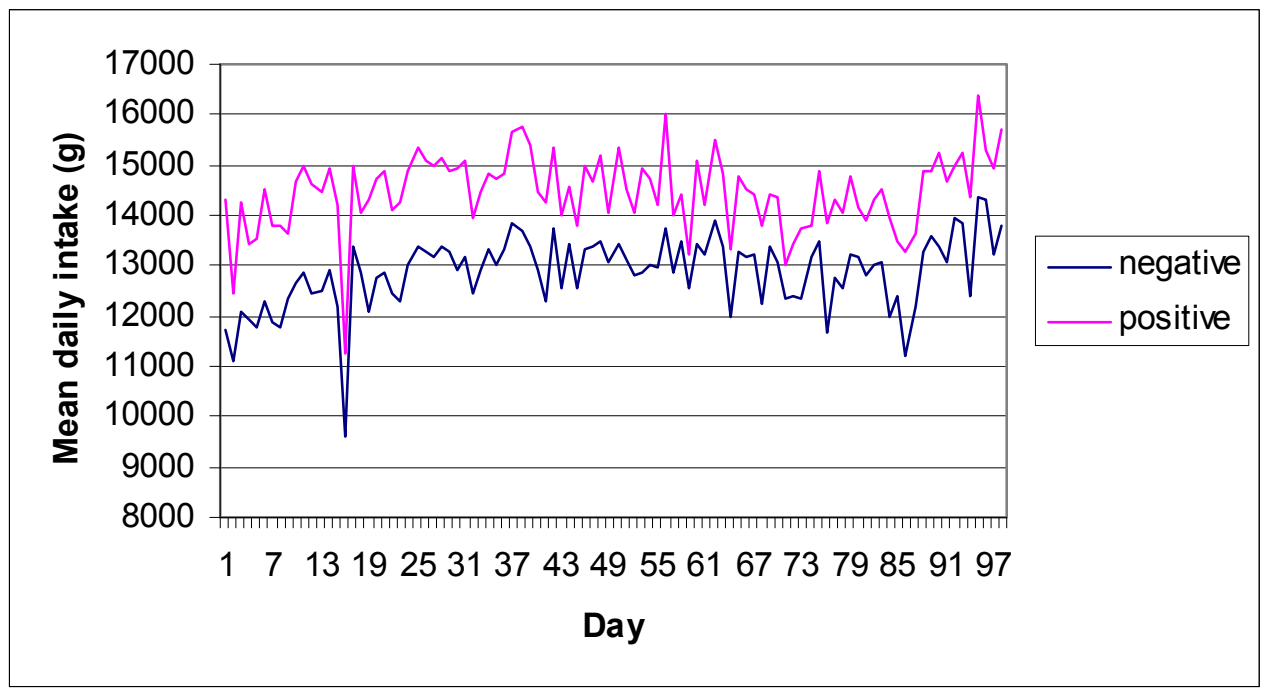

Figure 9. Mean daily intake for positive and negative RFI bulls. 